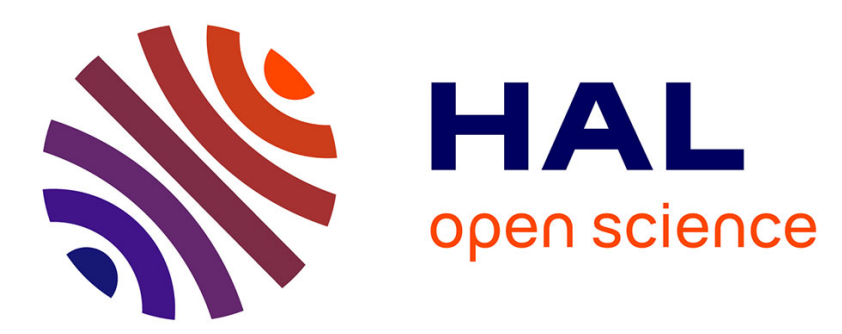

\title{
Capillary geochemistry in non-saturated zone of soils. Water content and geochemical signatures.
}

\author{
Marie Pettenati, Lionel Mercury, Mohamed Azaroual
}

\section{To cite this version:}

Marie Pettenati, Lionel Mercury, Mohamed Azaroual. Capillary geochemistry in non-saturated zone of soils. Water content and geochemical signatures.. Applied Geochemistry, 2008, 23, pp.3799-3818. 10.1016/j.apgeochem.2008.10.002 . insu-00356838

\section{HAL Id: insu-00356838 \\ https://hal-insu.archives-ouvertes.fr/insu-00356838}

Submitted on 5 Feb 2009

HAL is a multi-disciplinary open access archive for the deposit and dissemination of scientific research documents, whether they are published or not. The documents may come from teaching and research institutions in France or abroad, or from public or private research centers.
L'archive ouverte pluridisciplinaire HAL, est destinée au dépôt et à la diffusion de documents scientifiques de niveau recherche, publiés ou non, émanant des établissements d'enseignement et de recherche français ou étrangers, des laboratoires publics ou privés. 


\title{
Capillary geochemistry in non-saturated zone of soils. Water content and geochemical signatures
}

\author{
Marie Pettenati $^{a, b,}$, Lionel Mercury $^{b, c}$ and Mohamed Azaroual ${ }^{a}$

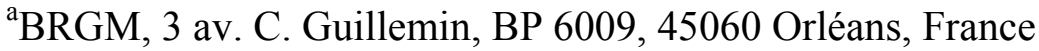 \\ 'UMR-CNRS 8148 “IDES”, Université Paris-Sud, bat. 504, 91405 Orsay, France \\ 'ISTO, UMR 6113 - CNRS/Université d'Orléans, 1A rue de la Férollerie, 45071 Orléans \\ Cedex, France
}

\begin{abstract}
The unsaturated zone (UZ) retains aqueous solutions against gravity by capillary forces. This suction state corresponds to a decreasing internal pressure of the water, which modifies its thermodynamic properties. Accordingly, the speciation of solutes and the solubility of solids and gases in such capillary solutions change. The volumetric capillary water content of the soil at high suction can be calculated extrapolating the water retention curves (WRC) with the Rossi-Nimmo model. Interestingly, several tens of liters per cubic meter of soil can be thus suctioned, a sufficiently large volume to support that: (1) capillary water is not restricted to nanosized pores, which means it disobeys the Young-Laplace law and is metastable with respect to vapor (superheating); and (2) the geochemistry of capillary solutions might significantly influence the subsurface mass transfer. Two field situations are here interpreted using the capillary thermodynamic properties: (1) the trapping of sand grains during the growth of desert roses (gypsum), and (2) the development of abnormal paragenetic sequences in some saprolites.

The capillary approach is extended to the soil solids, so that the micro-mineralogy can be explicitly (though sketchily) integrated in the calculations. The key conclusion is that capillarity changes the saturation indexes (and so the reaction rates) at given solution composition, in a way consistent with the field observations. This perspective amounts to geochemically distinguishing the capillary and percolating solutions, which is interestingly analogous to the immobile and mobile water distinction already often integrated in UZ flow models.
\end{abstract}

\section{Introduction}

Numerous authors have studied the transport of solutions in the unsaturated, or vadose, zone (UZ), a porous, dynamic, and unconfined medium (e.g. [Köhne et al., 2004], [Alletto et al., 2006] and [Mathias et al., 2006]). As the interface between the atmospheric systems and the aquifers, it plays a major role in the chemical signature of natural waters. Very early transport models integrated the physical parameters associated with the unsaturated state of the medium. Meanwhile, most attempts to develop a model coupling chemistry and transport through the UZ have assumed that properties of water and minerals are the same as those in the saturated zone (SZ). Recently, a physicochemical model of capillary water has been proposed where the chemical potential of the capillary water is explicitly calculated as well as its consequences on the thermodynamics of the capillary water-mineral-soil atmosphere system (e.g. [Mercury and Tardy, 2001], [Mercury and Tardy, 2004], [Mercury et al., 2003] 
and [Mercury et al., 2004]). The parameter proposed to control the capillary state within one given UZ is the relative humidity of the air in close-contact. (Mercury et al., 2003) and (Mercury et al., 2004) determined the effect of capillarity on the aqueous speciation and the solubility of minerals and gases in capillary solutions in general terms. Lassin et al. (2005) incorporated the osmotic aspects related to saline capillary solutions and tested this frame against some laboratory studies.

The objective of this study is to evaluate the potential influence of the capillarity at the macroscopic scale of the soil profile, especially considering the low volume expected for the capillary systems. A brief review of the basic principles of the physical chemistry of capillary water allows proposing that the capillary water is not compulsorily restricted to the nanoporous spaces, as usually deduced from the Young-Laplace law. Then, the volumetric capillary water content is quantified extrapolating the water retention curves (WRC) at high suctions with suitable models (e.g. [Ross et al., 1991], [Campbell and Shiozawa, 1992], [Rossi and Nimmo, 1994] and [Morel-Seytoux and Nimmo, 1999]). This extrapolation results in a surprisingly large volume of capillary water, but in agreement with what drying experiments measured. The capillary geochemical frame is then applied to field data from various studies, to illustrate: (1) which parameters and data are required to involve capillarity in geochemical approaches; and (2) which degrees of freedom capillarity might afford in the modeling of the subsurface systems. The first example concerns mineralogical observations collected on "desert roses", gypsum, and barite rosettes formed in arid environments that sometimes trap sand grains from local sediment during their growth. The second example tests the influence of capillarity on the weathering of a granite profile leading to the formation of a ferrallitic soil. These are neither case studies (above all because datasets are patchwork from different sources) nor real proofs of the predominant role of capillarity in the UZ. The aim of such simulations is to make the capillary interpretation of mineralogical paragenesis a local probe of dryness conditions in soil, at the aggregate level.

\section{Properties of capillary systems and theoretical background}

One of the particularities of the UZ is that it places in physical contact (i) atmospheric air; (ii) a solution of variable composition (that depends on both depth and interaction time with the solid matrix), either percolating as free water or held in pores by capillarity; and (iii) minerals and organic matter. Geochemically, the coexistence of two types of water (percolating vs. capillary), each having its own spatial and time dynamics of interactions with solids, organics and air is a basic characteristic of the soil systems.

\subsection{Capillary water}

Plane water-air interfaces (as in water tables, lake surfaces, etc.) express a physical equilibrium: water and air are at the same pressure, in general atmospheric pressure. Curved interfaces mean that pressure changes across them; in the case of concave capillary menisci, the pressure decreases from the atmosphere to the liquid. This is the Young-Laplace law (Fig. 1)

\section{$\underline{\Delta P=P_{\mathrm{LIQUID}}-\underline{P}_{\mathrm{VAPOR}}=2 \gamma / r}$}

where $\gamma$ is the liquid-air surface tension $\left(\mathrm{J} \mathrm{m}^{-2}\right)$ and $r$ is the radius of the curved spherical interface $(\mathrm{m})$. 
But liquid-air interfaces obey a further (chemical) condition: the liquid-to-vapor equilibrium. In case of plane interfaces, it is easily calculated and usually plotted in the $P-T$ diagram of water by the saturation curve (Fig. 2), where vapor and liquid are at the same chemical potential. As for the curved interfaces, the chemical potential of liquid water is modified by the pressure effect and so the saturation equilibrium: this is the Kelvin law (Fig. 1, see right ordinate axis, and Fig. 3; e.g. Mercury and Tardy, 2001 for more details)

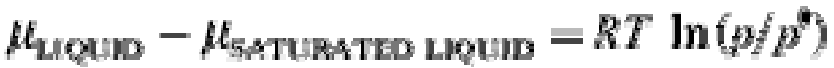

$=\int_{1}^{P} y_{\mathrm{n}_{2} \mathrm{~F}^{*}} \cdot \mathrm{d} l^{2}$

where $\mu$ is the chemical potential of the subscribed substance $\left(\mathrm{J} \mathrm{mol}^{-1}\right), R$ the ideal gas constant $\left(\mathrm{J} \mathrm{mol}^{-1} \mathrm{~K}^{-1}\right), T$ the temperature $(\mathrm{K}), p$ the vapor pressure at equilibrium with a curved interface $(\mathrm{MPa}), p^{0}$ the saturated vapor pressure (plane interface) $(\mathrm{MPa}) ; \underline{V}_{\underline{\mathrm{H}} 2 \mathrm{O}, \underline{p}}$, the molar volume of water as a function of pressure $\left(\mathrm{cm}^{3} \mathrm{~mol}^{-1}\right)$, and $P$ the water internal pressure (MPa).

Eq. (2a) and (2b) means that the concave curved liquid does not evaporate at vapor pressure lower than the saturated vapor pressure (dry atmosphere), down to a new "dry atmosphere saturation curve" (Fig. 3). It could be said otherwise that water vapor (like gases in general) has an increasing solubility in capillary water and so a decreasing pressure at equilibrium (e.g. Mercury et al., 2004).

Eqs. (1) and (2a) and (2b) make clear that the liquid pressure decreases in capillary phenomena but this is restricted to certain limits. In contrast to the usual idea, the limiting water pressure for condensed (liquid or solid) matter is not the zero pressure (which is the limiting pressure for gases), but the ( $P, T)$ spinodal pairs (Fig. 2) defined by the thermodynamic stability conditions (nil second derivative of the internal energy; e.g. Debenedetti, 1996 or Mercury et al., 2003). The $P-T$ space limited by the saturation and the spinodal curves is the domain of the superheated (metastable) water, either heated in excess of the saturation temperature or decompressed below the saturation pressure. Indeed, capillary water has a decreasing internal pressure and so plots inside the superheating domain. This fact offers a very useful perspective: capillary water has the same properties as superheated water which can be easily calculated extrapolating the equation of state (EoS) (e.g. [Mercury and Tardy, 2001] and [Mercury et al., 2003]).

What makes capillarity different from superheated water is the second characteristics involved in Eq. (1): the decreasing liquid pressure relates to a decreasing size of the liquid-air interface (controlled in real world by the thinness of the porous spaces). And the interface size is rapidly nanometrically-sized when liquid pressure decreases (Fig. 1). Why does the pore size make capillarity different from superheating? Actually, the transformation from liquid to vapor requires a certain quantity of triggering energy (the so-called activation energy): a gasliquid interface must be created (bubble nucleation) increasing the system energy by $4 \pi r^{2} \gamma$ (for a spherical bubble with radius $r$, and $\gamma$ the liquid-vapor surface tension), while the formation of the most stable phase brings back bulk energy $\left(4 / 3 \pi r^{3} \Delta P\right.$, with $\left.\Delta P=P_{\text {liquid }}-P_{\text {vapor }}\right)$. After the Classical Nucleation Theory (CNT), the competition between 
these two opposite effects results in a maximal energy barrier $E_{\mathrm{b}}$ (for more details, e.g. Debenedetti, 1996 or Caupin and Herbert, 2006)

$\underline{E_{\mathrm{b}}} \underline{=4 \pi r^{2} \gamma-4 / 3 \pi r^{3} \times \Delta P=(16 \pi / 3)\left(\gamma^{3} / \Delta P^{2}\right)}$

reached for a spherical bubble of "critical" radius $r_{\mathrm{c}}$ obeying the Young-Laplace law: $r_{\mathrm{c}}=2$ $\gamma / \Delta P$.

In other words, the bubble required for the capillary (superheated) liquid to vaporize is of the same size as the capillary container itself: the vaporization of capillary liquid obeying the Young-Laplace condition cannot occur due to geometrical restriction.

The key conclusions of this section and the previous equations are the following:

- It is possible to "capillarize" liquid water (that is to decrease its internal pressure, even down to the negative pressure domain) by the dryness of the atmosphere, instead of evaporating it;

- If the capillary radius obeys the Young-Laplace law, capillary water is a stable liquid because the internal tension of the liquid cannot be relaxed by nucleation due to the thinness of the pores.

\subsection{1. “Capillarizing” the water by the dryness of the soil atmosphere}

In UZ systems, the chemical potential of vapor in air drives the chemical potential of liquid water. The aqueous solution trapped in the UZ pores with fairly dry air, can avoid evaporation decreasing its internal pressure and so becoming a capillary liquid. The soil air humidity is related to the dryness of the external atmosphere and its seasonal behavior, to the consequent dryness gradient between the top surface and the soil depth (which generates a high suction force), to the depth of penetration of the evaporation uptake, to the local water uptake by plants in depth, and also in general to the soil heterogeneity. Obviously, the true question is to know how dry can a soil atmosphere be. Usually, the soil humidity is considered close to saturation below the first centimeters of the soil even in arid conditions, from field measurements and because soil wetting is much more rapid than soil drying. Two types of counter-arguments are now presented.

The first type comes from some field measurements, pointing to a more contrasting situation than usually argued. Andraski (1997) measured the matric potential with psychrometers (valid range: $\Psi>-8 \mathrm{MPa}$ ) and the water content by neutron probes in the Mojave Desert (USA) during a 5-a period. Water potentials decreased seasonally below the detection limit of the psychrometers, with associated volumes of water ranging between 0.02 and $0.19 \mathrm{~m}^{3} \mathrm{~m}^{-3}$ at depths between 0.15 and $1.25 \mathrm{~m}$. Scanlon et al. (2003) measured the matric potential in the Chihuahuan desert (Texas) during May through September 1989: psychrometers went out of range $\left(\Psi_{\mathrm{m}}<-8 \mathrm{MPa}\right)$ down to $0.8 \mathrm{~m}$ deep throughout most of the monitoring period. Finally, Flint et al. (2002) measured matric potentials in the Mojave Desert (Western USA) with a heat dissipation sensor, and recorded $\Psi_{\mathrm{m}}$ around $-100 \mathrm{MPa}$ from 40 to $80 \mathrm{~cm}$ deep.

The second type of argument comes from some indirect observations. First of all, diverse species adapted to arid climates (as is the Californian chaparral species) have their xylem pressures at low values, down to $-10 \mathrm{MPa}$ ([Scholander et al., 1965] and [Tyree and 
Zimmermann, 2002]). This allow them to extract water suctioned at strong capillary conditions, which points to arid conditions in soil at least along their root depth (down to 10$15 \mathrm{~m}$ ). Secondly, the interpretation of pedological profiles made by Tardy and collaborators (see especially [Tardy and Nahon, 1985], [Trolard and Tardy, 1987], [Trolard and Tardy, 1989] and [Tardy and Novikoff, 1988]) on tropical soils old enough to expect a chemical evolution obeying the thermodynamic equilibrium are considered. They observed that many mineralogical assemblages, at the aggregate and at the soil profile levels, indicate local arid conditions (what they called concretions), while coexisting at short distance with assemblages characteristic of more humid conditions (what they called excretions). Finally, work on waste rock piles (e.g. Stockwell et al., 2006) has shown intense weathering in the unsaturated pile together with strong variations of pore water chemistry, evidencing the short-scale heterogeneity characterizing geochemical behavior inside the pile.

These arguments point to a possible occurrence of strong capillarity in certain soil compartments possibly disconnected from the other ones. This disconnection of capillary water helps to establish capillary conditions and attainment of chemical equilibrium (or close): a local equilibrium included in strongly disequilibrated systems.

\subsubsection{Capillarity and size of pores}

A direct consequence of one capillary situation is that the liquid is now under a lower pressure than the atmospheric compartment, so that the capillary menisci are concave towards the atmosphere. This concavity depends quantitatively on the pressure difference, so that it is possible to calculate the corresponding radius of the capillary meniscus. Additionally, it is possible to relate the meniscus radius to that of the trapping pore taking care of the so-called contact angle and the thickness of adsorbed films, always present at the solid surface (see Mercury and Tardy, 2004, for more details).

The fundamental interest of this relationship can be highlighted by stressing that the YoungLaplace radius in Eq. (1) equals the critical radius of the growing nucleus of Eq. (3). Actually, the capillary liquid is "back-stabilized" by the geometrical restriction. The usual consequence is to assume that capillary water takes place only in such pores obeying the Young-Laplace law, namely nanosized pores.

Notwithstanding, it must be stated that it is difficult to know if the capillary systems obey the Young-Laplace equation, that is to know how stable they are. For instance, it has been demonstrated that the occurrence of metastable water in tensiometers readily enlarges the measurement range of this technique down to $-0.14 \mathrm{MPa}$ (Tamari et al., 1993). Also noticeable, aqueous solutions are able to reach high levels of superheating before nucleating (e.g. Zheng et al., 1991). The key argument is therefore that capillary water may disobey the Young-Laplace law, being located in larger pores than those predicted by Eq. (1). In this case, capillary (metastable) water can occupy the microporous spaces, with large associated volume, but, as a metastable compound, has a limited lifetime: is this lifetime long enough for the capillary water to be of consequence?

\subsubsection{Capillary water: stable or metastable?}

Whenever capillary liquid is located in pores larger than the nanopores (Young-Laplace), it acquires a metastable character which makes it able to nucleate vapor bubbles at any moment. How can the lifetime of the metastable liquid be assessed? 
According to the classical nucleation theory (CNT), the nucleation rate of vapor bubble follows an Arrhenius law (e.g. Debenedetti, 1996)

$$
F=F^{2} \exp \left(-E_{b} f R T\right)
$$

with $J$ the number of nuclei per $\mathrm{m}^{3}$ and per $\mathrm{s}, J^{0}$ a kinetic pre-factor, $E_{\mathrm{b}}$ the nucleation barrier of Eq. (3). The nucleation probability $p$ in a volume $V$ and during a time $\tau$ is

$$
p=1-\exp \left(-n^{r} \tau\right)
$$

Nucleation is assumed to occur when $p=1 / 2$. Then, the median value of duration $\tau_{\mathrm{m}}$ required to get at least one vapor nucleus is

$$
\tau_{n+}=\ln (2) / h^{r}
$$

Then, the time necessary to create a bubble nucleus depends on the space available to the fluid. In other words, if $1 \mathrm{~s}$ is sufficient to create one nucleus in a volume of $1 \mathrm{~L}$, more than 11 days are required in a volume of $1 \mathrm{~mm}^{3}$, and statistically, almost $32 \mathrm{ka}$ are necessary in a volume of $1000 \mu \mathrm{m}^{3}$, which is a typical size for interstitial pores in most natural porous media. This calculation is made at $J$ constant, namely at a given value of $E_{\mathrm{b}}$, which depends on the metastable "intensity" and the occurrence of heterogeneous nucleation (due to other chemicals than water in the liquid or to solid surface singularities). Eventually, at constant physico-chemical conditions, nucleation is an event that becomes rare in a small container.

The key conclusion here is that the lifetime of metastable liquid can be long enough for the capillary liquid to act on natural processes. The second conclusion is probably much more important for soil physics: associating capillarity to nanoporous spaces is too restricting, and capillarity can occur inside the microporosity what extends considerably its potential domain of influence.

\subsubsection{Capillary thermodynamics}

Now, the modeling of geochemical "capillary reactions" requires knowing the thermodynamic properties of the capillary compounds, and primarily those of the capillary water. It was noted above that capillary water is in the same state as superheated liquid, that is "normal" liquid put at pressures below the saturated ones (including the negative domain). Assuming that the Equation of State (EoS) can be extrapolated in the negative pressure range (an assumption discussed in [Mercury and Tardy, 2001], [Mercury and Tardy, 2004] and [Mercury et al., 2003]), the thermodynamic properties of capillary water can be readily calculated down to the extreme tensile stress liquid water can intrinsically sustain, defined by the spinodal curve (e.g. Mercury and Tardy, 2001): around $22 \% \mathrm{RH}$ at $0{ }^{\circ} \mathrm{C}$ and $35 \% \mathrm{RH}$ at $100{ }^{\circ} \mathrm{C} \mathrm{(Fig.} 2$ and Fig. 3 ). At RH lower than the spinodal plots, only the liquid water whose thermodynamic properties are not described by the EoS can continue to exist, for instance the adsorbed water films.

\subsection{Capillary solutions}

The capillary state of liquid water is assumed to have a direct feed-back on the dissolved solutes (Mercury et al., 2003), and so their thermodynamic properties are calculated 
extrapolating a convenient EoS (e.g. Tanger and Helgeson, 1988) down to negative pressures. That allows evaluation of how the capillary state impacts the reaction in aqueous solutions, as are complexation equilibria. The change of complexation equilibrium constant $K_{\mathrm{c}}$ at constant temperature as a function of solution pressure is

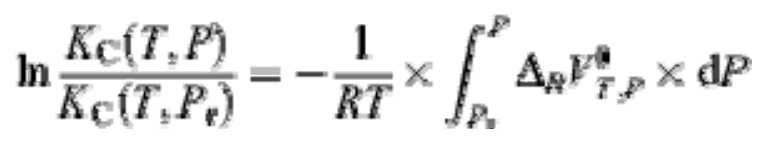

where $\Delta_{R} V^{0}$ is the volume change of the reaction $\left(\mathrm{J} \mathrm{MPa}^{-1} \mathrm{~mol}^{-1}\right), R$ the ideal gas constant $\left(\mathrm{J} \mathrm{mol}^{-1} \mathrm{~K}^{-1}\right), T$ the temperature $(\mathrm{K})$ and $\mathrm{d} P$ the change in pressure $(\mathrm{MPa})$. In the case of soil water, the term $\mathrm{d} P$ is negative. Mercury et al. (2003) showed that negative pressure of the water solvent promotes (in general) complexation due to the increasing (in general) volume of reaction when pressure decreases.

\subsection{Capillary solids}

The case of minerals in contact with capillary water deserves a special mention. Theoretically, the Young-Laplace law applies also to the mineral-solution interface so that any combination of pressures may exist at each side of the interface. Three main cases are presently considered to calculate the stability of minerals (noted 2 and 3 ) in one capillary solution (noted 1).

The first mineral-solution configuration is called isobaric: all the system is under capillary pressure $\left(P_{1}=P_{2}=P_{3}\right)$. A typical example of such a situation arises when cooling a superheated fluid inclusion containing liquid water: the melting temperature is increasing which means that ice and water are put under negative pressure (Roedder, 1967). The isobaric case arises when the stretched water pulls sufficiently upon the surrounding solid to which it is anchored, so as to distort its crystalline network (at least close to the surface) in a way similar to a mechanical traction (by clamps for instance). By analogy with the liquid-air meniscus, the flatness of the solution-solid interface points to a similar pressure from each side of the interface. In other words, a planar crystal face would point to isobaric conditions of the solution-solid interaction.

Two anisobaric configurations have been proposed: (1) solids with pressure different from water pressure $\left(P_{1} \neq P_{2}=P_{3}\right)$; and (2) pressure of the weathering solid different from that of the water and of the secondary solid $\left(P_{1}=P_{2} \neq P_{3}\right)$ ([Mercury et al., 2003] and [Lassin et al., 2005]). A simple example of such anisobaric configuration takes place in porous media when measuring a decreasing melting point of liquid water as a function of pore radius (GibbsThompson equation). In this case, the solid and the solution pressures are different because their mutual interface can change according to the Young-Laplace equation. That amounts to applying Eq. (1) to the solid-solution equilibrium, with $\gamma$ the solution-solid surface tension. Then, the curvature of the solution-solid interface is a function of the pressure disequilibrium at each side of the interface.

Therefore, the isobaric/anisobaric scenario relates to the shape of the solid, but this relationship leads to two difficulties. First, very often, solids are not isotropic as are liquids. The faceting of a polyhedral crystal shows that the surface tension depends on the crystal faces.

Second, the solution-solid surface tension (or those per crystal faces) is not constant through the change of physico-chemical conditions. Therefore, a quantitative approach requires 
knowing the aqueous solution-solid surface tensions (without speaking of those per crystal faces), as well as their dependency on the solution pressure, or on the solution salinity, or still on the shape/size of the solids (e.g. the review by Wu and Nancollas, 1999). Unfortunately, all this information is not available in general, so that the "solid pressure" parameter must be considered more as a simulation sketch than a field-based modeling choice. For the time being, the simplest approach of planar vs. curved minerals is used to translate into isobaric/anisobaric situations.

\subsection{Thermodynamic modeling of reactions in capillary systems}

The THERMO-ZNS computer code (e.g. [Lassin et al., 2003] and [Lassin et al., 2005]) was developed to calculate the thermodynamic properties of water, aqueous species, minerals, and gases in capillary systems based on two existing software packages: SUPCRT92 (Johnson et al., 1992) and Eqtest (Span and Wagner, 2000). The range of application of these software packages is extended in THERMO-ZNS to include the calculation of thermodynamic properties of liquid water in the capillary range. That amounts to calculating the liquid properties at $(T, P)$ pairs plotted in the capillary liquid (vapor stability) domain.

For the following equation:

$\underline{X_{\text {cristal }}}+\mathrm{H}_{2} \underline{\mathrm{O} \rightarrow Y_{\text {cristal }}}+\underline{\mathrm{Cat}^{+}+\mathrm{An}^{-}}$

the general equilibrium constant of reaction with pressure variation is

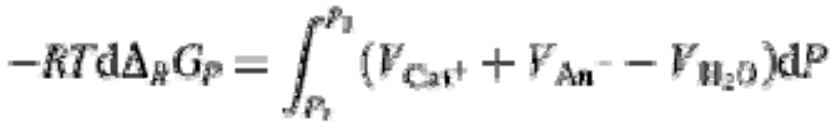

$$
\begin{aligned}
& +\int_{P_{R}}^{P_{2}} V_{Y_{R i n+1}} d P \\
& -\int_{P_{r}}^{P_{3}} V_{X_{\text {sitial }}} \mathrm{d} P
\end{aligned}
$$

Eq. (9) enables to parameterizing each constituent of the reaction to its own pressure conditions. $X$ and $Y$ crystals can be at pressures equal or different from each other, and also from that of the solution (taken into account through $\mathrm{H}_{2} \mathrm{O}$, $\mathrm{Cat}^{+}$, and $\mathrm{An}^{-} V \mathrm{~d} P$ function). When one constituent remains at constant pressure inside a globally changing system pressure, its own $\mathrm{d} P$ is put to zero, and the equilibrium constant is calculated using the $\Delta_{f} G_{T, 1}$ of this constituent.

Fig. 4 shows the variations in the thermodynamic equilibrium constant $K$ of the anhydrite reaction (used here as an example) calculated with THERMO-ZNS under isobaric $\left(P_{\text {anhydrite }}=P_{\text {solution }}\right)$ conditions. $K$ diverges significantly from its value of $0.1 \mathrm{MPa}$ (variation greater than the margin of error) when the capillary pressure reaches $-20 \mathrm{MPa}(\mathrm{RH} \approx 86 \%)$. For internal solution pressures between zero (SZ) and -20 MPa, anhydrite has a thermodynamic behavior almost identical to its behavior under a pressure at $0.1 \mathrm{MPa}$. The absolute value of $K$ does not vary more than $4.5 \%$, which is within the range of error of estimation of equilibrium constant values cited in the literature. It should be noted that, 
capillary water cannot exist under the spinodal limit at $-200 \mathrm{MPa}$ at $25^{\circ} \mathrm{C}$. Finally, for an anhydrite-solution system at room temperature, the capillary water whose chemical behavior is significantly modified is associated with the interval $(-200 \mathrm{MPa} ;-20 \mathrm{MPa})$.

\section{Water retention curves (WRC) in the UZ: the $\Psi(\theta)$ relationship}

The so-called WRC are (empirical) correlations between capillary pressure and volumetric water content for different types of soils. The volumetric water content is the ratio of the water volume to the total volume of soil; usually noted $\theta$, it has no dimension. The capillary pressure is defined through the $\Psi_{\mathrm{m}}$ parameter, usually called either the suction or the matric potential. It represents the difference in pressure (in $\mathrm{MPa}$ ) between the air and the liquid phase, or equivalently the force per unit area holding the volume of water in the soil

$\underline{\Psi} \underline{\underline{m}}=P_{\text {water }} \underline{P_{\text {air }}}$

As soon as $P_{\text {water }}$ is lower than $0.1 \mathrm{MPa}, \Psi_{\mathrm{m}}$ is negative. Actually, the matric potential is nothing other than the $\Delta P$ in Eqs. (1) and (3), or $\mathrm{d} P$ in Eqs. (2b), (7) and (9).

The ability of the capillary state of the soil to significantly participate in the geochemical mass balance requires that the capillary water content be sufficiently large in the whole range of capillary pressures having geochemical significance $(-20,-200 \mathrm{MPa}$, see above).

\section{1. $\Psi(\theta)$ model adapted to high suction}

Most of the models commonly used (e.g. [Brooks and Corey, 1966] and [van Genuchten, 1980]) are poorly suited to calculating the volumes of water held at strong suction, especially due to the use of one residual water content parameter. Actually, this residual content in an expression of saturation is physically unrealistic: as the water content drops towards the residual water content, the suction increases towards an infinite value. Consequently, Ross et al. (1991) and Rossi and Nimmo (1994) incorporated into the Brooks and Corey (1966) model a finite suction value $\Psi_{\mathrm{D}}$ when $\theta=0$, postulating that the water content becomes approximately proportional to the logarithm of the suction in the strong suction range. The model is thus more consistent and better suited to calculating water contents held by strong suction.

The various models representing the $\Psi-\theta$ relationship are made up of several equations whose validity range is delimited by the characteristic values of the matric potential $\Psi_{\mathrm{m}}$. The ovendryness potential $\Psi_{\mathrm{D}}(\theta=0)$ corresponds to the suction associated with the RH around a soil sample in an oven at $105^{\circ} \mathrm{C}$. In a hermetically sealed room, with air varying between 0 and $40{ }^{\circ} \mathrm{C}$ and an $\mathrm{RH}$ between $5 \%$ and $95 \%, \Psi_{\mathrm{D}}$ suction values vary between $-1400 \mathrm{MPa}$ and $-470 \mathrm{MPa}$ (e.g. Ross et al., 1991). The average suction value $\Psi_{\mathrm{D}}$ normally used is $-1000 \mathrm{MPa}$. It is evident that, at this extreme suction, the capillary water has long since evaporated $\left(P_{\min }=-200 \mathrm{MPa}\right)$ and that this limit value integrates the adsorption films and the structural water.

The three equations making up the Rossi-Nimmo junction model (Eqs. (I), (II), and (III), see Appendix A) enable distinguishing three different behaviors of the retention capacity of a soil delimited by the analytical parameters $\Psi_{\mathrm{i}}$ and $\Psi_{\mathrm{j}}$. Eq. (I) describes the water-saturated domain, 
Eq. (II) the domain of progressive emptying of the pores in the moderate suction range, and Eq. (III) the domain of suctions near $\Psi_{\mathrm{D}}$.

The model was tested by Rossi and Nimmo (1994) using data from seven soils with different textures and a range of suctions covering at least six orders of magnitude. The model produced results in agreement with measured values (e.g. Campbell and Shiozawa, 1992), particularly in the range of strong suction. This validates the use of a finite suction value $\left(\Psi_{\mathrm{D}}=-1000 \mathrm{MPa}\right)$ for zero water content, and of a logarithmic function. Other studies also show the robustness of the model to account for the $\Psi-\theta$ measurements, even in the driest conditions (e.g. [Prunty and Casey, 2002] and [Cornelis et al., 2005]).

The present paper uses the same soils as Rossi and Nimmo (1994) to take advantage of this realistic (and validated) estimation of the water volumes held over a large range of suctions.

\subsection{Modeling WRC}

The water held by strong suction results from both adsorption and capillary retention processes. In this article, capillary water corresponds to the volume of water calculated between the minimum $\Psi_{\min }\left(\Psi_{\min }=P_{\min }-P_{\text {air }}\right)$ and maximum $\Psi_{\max }\left(\Psi_{\max }=P_{\max }-P_{\text {air }}\right)$ matric potentials (Fig. 5). The water held by suction between $\Psi_{\min }$ and $\Psi_{\mathrm{D}}$ can only be adsorption films. The volumes of water obtained using the parameters in Table 1 for a suction corresponding to $\Psi_{\min }$ and to suctions between $\Psi_{\min }$ and $\Psi_{\max }$ for various types of soil are given in Table 2.

Several liters to several tens of liters of water can be held per cubic meter of soil by strong suction, but that depends of course on the particle size distribution in the given soil. Hence, for the "sand L-soil", only $4.6 \mathrm{~L} / \mathrm{m}^{3}$ is held, whereas $34 \mathrm{~L} / \mathrm{m}^{3}$ is held in the "Salkum silt loam" (Table 2). To give an order of magnitude, based on the data of Hillel et al. (1998), a volume of 3-5 L of water $/ \mathrm{m}^{3}$ of sand represents the water content due to adsorption films (having an average thickness of $1 \mathrm{~nm}$; e.g. Low, 1961). The quantities of water obtained here are potentially 10 times greater than this content.

\subsection{Measured data and model results}

\subsubsection{Measurements in the field}

Different equipment is used for in situ suction measurement like tensiometer, psychrometer, and heat dissipation sensor. The water content is in general measured through indirect probes as are the time domain reflectometry (TDR). It is important to work with appropriate equipment corresponding to the soil suction range of the considered climate. Indeed measured suctions often exceed the detection limit of the equipment, even in a temperate climate.

It is in general expected that arid atmospheric conditions penetrate readily in the soil in the first centimeters below the soil surface. For instance, Ishizuka et al. (2005) studied the soil water content (by TDR probes) along the first $0.05 \mathrm{~m}$ in the Chinese Taklimakan desert, especially during October 2003 . At $0.01 \mathrm{~m}$ depth, the soil contained $10 \mathrm{~L} / \mathrm{m}^{3}$ at $40 \%$ soil RH (which translates into $-120 \mathrm{MPa}$ at $20^{\circ} \mathrm{C}$, the October local mean temperature) while at $0.05 \mathrm{~m}$ depth, the water content was $40 \mathrm{~L} / \mathrm{m}^{3}$ at $60 \%$ soil $\mathrm{RH}\left(\Psi_{\mathrm{m}}=-68 \mathrm{MPa}\right.$ at $\left.20{ }^{\circ} \mathrm{C}\right)$. 
These quantities and the associated suction are consistent with the WRC extrapolations and support the idea that capillary water volumes are far from negligible. It should be noted, that this tends to support the proposition that part of this volume is located in micropores, as metastable capillary water.

\subsubsection{Laboratory measurements}

In terms of retention capacity, natural materials were demonstrated to hold large volumes of water up to very high suction. For instance, McCrea et al. (1990) measured the retention capacity of granitic material weathered from the Yilgarn craton in SW Australia and found $50-60 \mathrm{~L} / \mathrm{m}^{3}$ of soil at $-125 \mathrm{MPa}(\mathrm{pF} 6.1)$. Assuming the granite-derived soil be approximated by a silt loam soil, the water content calculated according to the Rossi and Nimmo model is very close, though lower, to that measured (focus on $\theta\left(\Psi_{\max }\right)$ in Table 2$)$. Additionally, $-125 \mathrm{MPa}$ potential corresponds to arid conditions (air $\mathrm{RH}=40 \%$, at $T=35^{\circ} \mathrm{C}$ ), close to the mean value in this region from November to March (it varies between $30 \%$ and $40 \% \mathrm{RH}$ during this period; source: www.bom.gov.au).

The water content values measured on Darling Range bauxite (Kew and Gilkes, 2006) at different matric potential conditions also confirms the performance of the Rossi-Nimmo model at high suction. In fact, the measured values range from 40 up to $100 \mathrm{~L} / \mathrm{m}^{3}$, up to twice the present estimates. In addition, the Rossi and Nimmo model retrieves the water content for sand type soil ("L-soil", Table 2) measured by Mehta et al. (1994) in a Shonai sand dune soil sample down to $-25 \mathrm{MPa}$.

According to these dataset and the calculations, the WRC interpreted with the Rossi-Nimmo model tend to underestimate the capillary water volumes rather than to overestimate them. Moreover, these studies exemplify how natural samples can hold large volumes of capillary water, even at very high suction. This is highly consistent with previous studies which point to the easiness for water and aqueous solutions to occupy large parts of the metastable domain (e.g. Zheng et al., 1991). In reality, that means the humidity conditions in soils could be very heterogeneous, and that the way the soil suction is controlled at the annual scale, especially in arid and semi-arid climates, may suggest a stronger role of external atmospheric conditions than usually expected.

Based on this conclusion, a way to thermodynamically take the capillarity into account is now presented, detailing the required (though often lacking) information to do so.

\subsection{Export of capillary solutions along a granitic weathered profile}

One of the fundamental points concerning the application of the capillary method is to understand how the thermodynamic properties of capillary solutions influence geochemistry in the unsaturated zone-saturated zone continuum given the low hydraulic conductivities associated with strong suction.

When atmospheric RH is under $100 \%$, it can be assumed that, in the upper part of the soil, the water in the soil capillaries is in isolated water lenses with no direct hydraulic link to the water table. The aridity of the atmospheric reservoir, the distance between soil surface and a given pore and the vapor diffusion kinetics are all parameters that determines the possible humidity variations below the soil surface. When the atmosphere is too dry for a pore to hold water even in a capillary state, it empties and becomes a potential conduit for percolation 
during a rainfall event (percolating macropore). Meanwhile, the suction becomes rather strong in the micro-pores still filled with capillary water. It is the way to create the duality between mobile and immobile water (the hydraulic conductivity side), but that implies also a heterogeneity of capillary states (the matric potential side), here advocated. Therefore, the matric potential gradient between the two compartments should homogenize them during a rainy event which puts percolating water in contact with capillary water. But, first, these strong gradients are compensated by the water diffusivity, well-known to dramatically decrease with the matric potential, so that it can become even lower than the solute diffusion. Second, the connections between mobile and immobile water are not permanent by definition, so that both the solute diffusion and the water diffusivity cannot equalize the composition of the two compartments.

When such a Mobile-Immobile Model (MIM) scheme takes place over a sufficiently large volume of percolating water in macropores vs. retained waters in micropores, the chemical characteristics of solutions exported to the saturated zone depend on the intensity and extent of exchange between the mobile and immobile water. If it is considered that micropore water is retained at high suction, thermodynamic properties of capillary water are different from those of macropore water (free water) (e.g. [Mercury and Tardy, 1997a], [Mercury and Tardy, 1997b], [Mercury and Tardy, 2001], [Mercury et al., 2003], [Mercury et al., 2004] and [Lassin et al., 2005]). As the volume of water held at high suction in the microporosity can be important, a diffusive exchange with macroporosity, wherein renewed (from upward) solutions percolating along a soil profile (dynamic context), may contribute significantly to the mass balance at the UZ scale.

\section{Stability of minerals in the natural "capillary" environments}

\subsection{Capillarity and mineralogy of desert roses}

Shearman (1981) reported that grains of sand become embedded in gypsum crystals (desert roses) growing in Abu Dhabi sebkhas, in clearly defined zones. Gypsum minerals with "trapped" grains are found in temporary salt marshes, but not in nearby carbonate-watersaturated silt. This zonation is classically related to both the gypsum growth rate (rapid evaporation leads to high supersaturation), and the lack of cohesion (which facilitates the trapping in the growing crystals) of the grains of sand in the sebkhas compared to those in the silt.

The gypsum formation reaction is

$$
\begin{aligned}
& \mathrm{Ca}^{2+}+\mathrm{SO}_{4}^{2-}+2 \mathrm{H}_{2} \mathrm{O} \rightarrow \mathrm{CaSO}_{4}: 2 \mathrm{H}_{2} \mathrm{O} \\
& \text { where } \begin{aligned}
\Omega & =Q / K_{22}-m \text { and } Q \\
& =\frac{\left(\mathrm{CaSO}_{4}: 2 \mathrm{H}_{2} \mathrm{O}\right)}{\left(\mathrm{Ca}^{2+}\right)\left(\mathrm{SO}_{4}^{2-}\right)\left(\sigma_{\mathrm{x}^{2}}\right)^{2}}
\end{aligned}
\end{aligned}
$$

When the salinity increases due to evaporation, water activities decrease (square exponent) and the $\Omega$ (saturation ratio) increases with $Q$ causing supersaturation $(\Omega<1$, undersaturation; $\Omega=1$, equilibrium; $\Omega>1$, supersaturation) which finally leads to precipitation of gypsum. 
This is the solution-solid counterpart of the bubble nucleation with the same metastable (supersaturation) range before equilibrium is restored by nucleation.

The standard interpretation of desert rose formation refers to the role of water evaporation causing supersaturation, a very logical effect in the presence of dry air. However, the grain engulfment of sand is more difficult to explain, which is generally overlooked. Actually, when one crystal is growing, it can either push away a close particle or engulf it, depending on the ability of the system to suck (or not) liquid fast enough in the crystal-particle gap to prevent (or not) the two from joining (e.g. [Corte, 1962], [Kastner, 1970] and [Scherer, 1999]). The key parameter is the growth rate which must exceed what is usually called the critical velocity to enable the engulfment. It is well-known that increasing the supersaturation increases the growth rate. Therefore, there is a threshold effect: supersaturation must be high enough to allow the growth rate to be greater than the critical velocity. In general, the nucleation supersaturation threshold of gypsum is rather low due to its high solubility and its associated low solution-solid surface tension (Putnis et al., 1995). Thus, evaporation appears able to concentrate the solution and makes it supersaturated but this effect may be not strong enough for gypsum to account for the grain engulfment associated with the desert roses.

It is possible to try to interpret the process including the capillarity features. The low atmospheric $\mathrm{RH}$ values (23\% in May to 44\% in December, after Abu Dhabi NOAA meteorological station, http://www.climate-charts.com) may lead to very negative water pressures in microporous environments, even in a coastal area (in the supratidal zone). The working outline is to consider localized low-RH micro-media where the capillary liquid water bridges the grains of sand. These bridges make the grains "stick" together inside the globally non-cohesive sandy matrix, while maintaining a certain geometrical separation between these grains (analogous to a beach situation). If the solution does not evaporate but becomes capillary, the equilibrium constant decreases due to the RH changes which modifies the chemical potential of the solution, and then the supersaturation $(Q / K)$ rises automatically. This effect can be described by

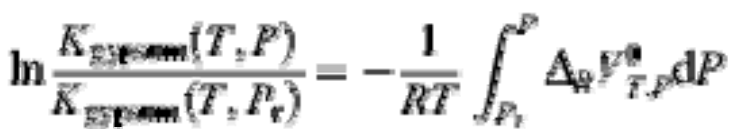

where $K_{\text {gypsum }}(T, P)$ is the thermodynamic equilibrium constant of reaction (11) at $25^{\circ} \mathrm{C}$ and negative pressure and $K_{\text {gypsum }}\left(T, P_{\mathrm{r}}\right)$ is the thermodynamic equilibrium constant of the same reaction at the same temperature and standard pressure $(0.1 \mathrm{MPa})$. The consequences of the $\mathrm{RH}$ drop are here evaluated at constant salinity (namely, at constant $Q$ in Eq. (12)), the capillary peculiarities being assumed through the $V \mathrm{~d} P$ term by the equilibrium constant $K$. The solid pressure/texture effect can be loaded developing the $\Delta_{r} V \mathrm{~d} P$ term

$$
\begin{aligned}
& -R T d \Delta_{R} G_{P}=\int_{P_{1}}^{P_{1}}\left(V_{\mathrm{Ca}^{+}}+F_{\mathrm{An}^{-}}\right. \\
& \left.-V_{\mathbf{A}_{2}} 0\right) d P_{1} \\
& -\int_{P_{\mathrm{T}}}^{P_{2}} \nabla_{\text {swann }} \mathrm{d} P_{2}
\end{aligned}
$$

The only solid involved in the reaction can be at the same pressure as that of the solution ( $\left.\mathrm{d} P_{1}=\mathrm{d} P_{2}\right)$ or not (for instance: $\mathrm{d} P_{2}=0$, solid pressure does not vary with the capillarization 
of the solution). The fact that the outer crystal faces of desert roses extend as planar faces indicates an isobaric scenario, according to which growing gypsum and capillary solution both undergo capillary pressure (that is, $\left.\mathrm{d} P_{1}=\mathrm{d} P_{2}\right)$. $K_{\text {gypsum }}(T, P)$ calculated with THERMOZNS at $P_{\mathrm{w}}=P_{\text {gypsum }}$ results in a decreasing gypsum equilibrium constant with water pressure (Fig. 6): the capillary state generates a supersaturation of gypsum at a constant value of $Q$ by decreasing $K_{\text {gypsum. }}$. Thus, as the bridged solution becomes supersaturated with respect to the gypsum, its precipitation can envelop the grains the capillary solution was anchored to, a mechanical link which makes easy the engulfing of the sand particle: at the extreme, the engulfment becomes independent of the growth rate.

To go further, the gypsum precipitation reaction was simulated with PHREEQC (Parkhurst and Appelo, 1999), taking into account the kinetic parameters controlling the reaction (Kuechler et al., 2004). A solution of pure water in contact with $1 \mathrm{~g} \mathrm{CaSO}_{4}: 2 \mathrm{H}_{2} \mathrm{O}$ was subjected to a matric potential of $-100 \mathrm{MPa}$ (corresponding to $48 \% \mathrm{RH}$, close to external air values; see also the arid soils potentials from Flint et al., 2002) and compared to what arises when subjected to a zero matric potential (SZ water at piezometric level). The reaction rate $\left(\mathrm{mol} \mathrm{s}^{-1}\right)$ is expressed as a function of the total reactive surface (SA) of the mineral assuming a specific surface for gypsum of $51 \mathrm{~cm}^{2} \mathrm{~g}^{-1}$, and as a function of the kinetic constant $k_{25}{ }^{\circ} \mathrm{C}$ of $1.1 \times 10^{-7} \mathrm{~mol} \mathrm{~cm}^{2} \mathrm{~s}^{-1}$. Eq. (15) is a kinetic law simplified after Lasaga (1998).

$\operatorname{rak}=\mathrm{SA} \times\left(\frac{m}{m_{n}}\right)^{F} \times \mathrm{K}_{\mathrm{S}} \times(1-\Omega)$

where $\Omega$ is the saturation ratio $(Q / K)$ of the mineral, $p$ is the factor enabling taking into account the variation in the reactive surface during the reaction $(p=0.67), m_{0}$ is the initial number of moles of the mineral, and $m$ is the number of moles at time $t$. The term $\Omega=Q / K_{\text {gypsum }}$ calculated with THERMO-ZNS takes into consideration the capillary effect on the equilibrium constant and then on the reaction rate (Fig. 7A). In $-100 \mathrm{MPa}$ capillary solution, the rate decreases much more rapidly than in free water indicating that saturation is reached more rapidly. Taking into account the capillary pressure of water, it was observed that the $\mathrm{Ca}$ concentration at equilibrium with the gypsum is well below that calculated for $0.1 \mathrm{MPa}$ (Fig. 7B). The decrease in the equilibrium constant $K_{\text {gypsum }}$ associated with the kinetic law (Eq. (15)) for a solution pressure of $-100 \mathrm{MPa}$ under isobaric conditions leads to a notable decrease in the equilibrium constant of gypsum so that the crystallization rate can become sufficiently high to exceed the critical velocity leading to an absorption of the sand grain rather than to it being pushed away.

Eventually, it is stressed, that the required supersaturation can be met either by rapid and intense evaporation which increases the ionic activity product of gypsum $(Q)$ which is the usual explanation, or by strong "capillarization" of the solution which decreases its equilibrium constant $(K)$ at constant value of $Q$ which is the presently proposed mechanism. Obviously, evaporation and capillarization are not exclusive from each other and may act together to cooperatively increase the supersaturation and then the reaction rate, which anyway has to exceed that of the critical particle-pushing velocity.

\subsection{Capillarity and the inversion of paragenetic sequences}

The spatial distribution of secondary minerals developed by in situ isovolumetric weathering of granitic and/or magmatic rocks is generally correlated with a thermodynamic stability 
sequence that is clearly vertically differentiated from top to bottom, as solutions percolate in a homogeneously-distributed porous material and become saturated with these minerals. Base cations and silica are released and the relative accumulation of the elements leads to the neogenesis of crystals like alumina (gibbsite) and crystalline Fe hydroxides (goethite and hematite). Clays like kaolinite are entirely neogenic and result from the recombination of the alumina and the remaining silica of upper horizons (e.g. [Fouillac et al., 1977] and [Duchaufour, 2001]).

The nature of the secondary minerals depends on the percolating rate of water through the system and on the differential solubility of the constituents as a function of soil $\mathrm{pH}$. This intense weathering, dominated by geochemical controls, leads to the creation of a ferrallitic soil type. From the top to the bottom of the weathered granitic and/or magmatic rock, the "normal" succession of secondary minerals can be distinguished: pure gibbsite horizon, pure kaolinite horizon, lithomarge (the deeper horizon of the granite weathering sequence, base of ferrallitic tropical soils) with quartz, and kaolinite (Fig. 8A). However, this "normal" thermodynamic stability sequence is only rarely observed in the natural environment (e.g. Lucas et al., 1996) with observed lateral variations of the mineralogical composition. For instance, kaolinite predominates in microporosity of surface horizons and in compact horizons of clayey loam and can coexist with gibbsitic material in the macroporosity of ferrallitic soils, which contain additionally the usual oxisol mineralogical sequence (Fig. 8B) (e.g. [Furian et al., 2002] and [Mutakyahwa et al., 2003]). This organization is not consistent with the thermodynamic stability of gibbsite and kaolinite in contact with a solution percolating through the soil profile: it is why they are defined as "abnormal" profiles.

The interpretation of these profiles is still an open problem (Bourman, 1993), even if one dominant explanation relates to microbiologic activity (e.g. Lucas et al., 1996). However, it cannot explain why gibbsite and goethite coexist at the same depth in the highly permeable zones (macroporosity), whereas kaolinite and hematite are stable in the highly impermeable zones (microporosity) (e.g. Krönberg et al., 1982). Hematite precipitates in the small pores delineated by the kaolinite crystals, whereas goethite precipitates preferentially in large interaggregate porosity (e.g. [Tardy and Novikoff, 1988] and [Anand et al., 2002]). Thus, Tardy and Novikoff (1988) were able to propose that a "wet" paragenesis takes place in the large pores (hydrated minerals: goethite-gibbsite) dominated by humid conditions, while a "dry" paragenesis locates in the small pores (anhydrous minerals: kaolinite-hematite) inside which high suction conditions proposedly exist. The same idea is the basis for the thermodynamic reconstitutions of (Trolard and Tardy, 1987) and (Trolard and Tardy, 1989) extended to all saprolite minerals, namely at the soil profile scale (Fig. 12). In other words, the mineralogy of Fe oxides is controlled by exchange mechanisms between macroporosity and the microenvironments, namely results from a compromise between the drainage conditions in the large pores and the aridity in the small pores, itself due to their limited accessibility in the porous medium. An attempt was made to use the capillary geochemistry at the soil profile scale to account for the inverted paragenetic sequences. As the required datasets were not available, a simulation gathering the information from various sources was performed.

\subsubsection{Mineralogical assemblage and pore solution}

The first step to simulate the weathering is to choose the pore solution as well as the primary minerals sequence. 
Ferrallitic soils develop from mafic to ultramafic bedrocks whose mineralogical composition has been abundantly studied (e.g. [Fritz, 1975], [Krönberg et al., 1982], [McCrea et al., 1990], Duchaufour, 2001 Duchaufour, P., 2001. Introduction à la science du sol. Sol, végétation, environnement, sixth ed. de l'Abrégé de pédologie. Dunod éditions, Sciences de la nature et de la vie, France.[Duchaufour, 2001], [Anand and Paine, 2002], [Furian et al., 2002] and [Mutakyahwa et al., 2003]): the association of quartz, plagioclase, K-feldspar, biotite, and hornblende seems the best association to lead to ferrallitic or saprolitic soil. The chosen pore solution was that measured in the field by White et al. (1998), because the sampled saprolite has a composition (Table 3 ) very similar to the selected mineral sequence.

The temperature was supposed constant at $25^{\circ} \mathrm{C}$, while the solution pressure ranged from $-150 \mathrm{MPa}(30 \% \mathrm{RH})$ to $0.1 \mathrm{MPa}(100 \%)$. Concerning the solid pressures, the isobaric $\left(P_{\text {solid }}=P_{\mathrm{w}}\right)$ and anisobaric $\left.P_{\mathrm{w}} \neq P_{\text {solid }}=0.1 \mathrm{MPa}\right)$ conditions are systematically discussed.

The thermodynamic properties of the aqueous species, gases, minerals and reactions in the medium, under the pressure and temperature conditions of the UZ, are calculated with THERMO-ZNS. The equilibrium constants for the calculated reactions for each selected matric potential value $\Psi_{\mathrm{m}}$ are then loaded in a dedicated PHREEQC database.

\subsubsection{Effect of capillarity on mineral-solution interactions}

The equilibrium reactions for the minerals studied and corresponding $\log K(T, P)$ are given in Table 4. The saturation index $(\mathrm{SI}=\log Q / K)$ of the minerals varies as a function not only of the matric potential imposed on the pore solution but also of the mineral-solution interaction conditions, isobaric or anisobaric (Fig. 9 and Fig. 10). The greater the suction, the greater the increase in the SI of minerals under isobaric conditions. Thus, for initially-undersaturated minerals the distance to equilibrium decreases and therefore the dissolution is less favored. Equivalently, for initially-supersaturated minerals, capillarity under isobaric conditions enhances the stability of minerals. The capillary effect is to reduce the intensity of weathering and then appears as a stabilizing factor.

When the SI of the silicate minerals is calculated for anisobaric conditions, the capillary effect (Fig. 9 and Fig. 10a) increases the distance to equilibrium: these minerals tend to be more weathered when the soil aridity increases.

The effect of capillarity on the stability of the minerals capable of controlling the activity of $\mathrm{Al}^{3+}$ and $\mathrm{SiO}_{2}$ leads to modifing the mobility and the availability of these species. Interestingly, the SI shift calculated under isobaric conditions $\left(K_{\mathrm{p}} / K_{1}=1.3\right.$ to $\left.-150 \mathrm{MPa}\right)$ is more marked than that under anisobaric conditions $\left(K_{\mathrm{p}} / K_{1}=0.6\right.$ to $\left.-150 \mathrm{MPa}\right)$ (Fig. $\left.9 \mathrm{~d}\right)$. Therefore, the output of dissolved matter depends as much on the solution-solids equilibrium (texture vs. pressure change) as on the degree of suction.

Fig. 10b, c, and d show the behavior of Fe(III) minerals in relation to the capillary effect. The Fe hydroxides and silicates behave in the same way (opposite trends under isobaric and anisobaric conditions) whereas goethite and hematite follow the same trend. The high Gibbs free energy value for $\mathrm{Fe}(\mathrm{III})$ solids compensates for the energy variation of dissolved $\mathrm{Fe}^{3+}$ and water, the two keeping the trend similar despite the different textural situations. Anhydrite (Fig. 10e) behaves like goethite and hematite. Calcite behavior (Fig. 10f) is more contrasted with the SI decreasing from 0.1 to $-50 \mathrm{MPa}$ and then increasing to the highest suction values 
under anisobaric conditions, whereas isobaric conditions result in a continuous increase in SI with suction.

To narrow the predictions of the capillary model in the saprolite weathering case, it can be hypothesized that capillary solutions interact with primary minerals under anisobaric conditions (because they are inherited from bedrock), while the secondary minerals behave under isobaric conditions (control by the aqueous solution in which crystals are growing).

\subsubsection{Thermodynamic stability and volume ratio}

To incorporate this approach in a context of complete weathering, it is no longer simply a question of thermodynamic stability, but also of geochemical dynamics coupled with a volume of exported solutes. In general, if considering flow in a weathered profile of homogeneous poral distribution, under rapid drainage conditions, the base cations and silica are rapidly exported and thus enable the precipitation of Fe oxyhydroxides (goethite, hematite) and $\mathrm{Al}$ oxyhydroxides (gibbsite) (top of "normal" profile, Fig. 8A). For moderate drainage, the silica will tend to be immobilized and the bases eliminated from the profile, ensuring the stability of kaolinite (base of "normal" profile, Fig. 8A). Montmorillonite will be stable in environments where drainage is slow for a medium rich in base cations and silica. But secondary minerals produced by weathering can coexist within the same horizon as a result of variations in flow velocity between macro and micro-pores (Fig. 8B).

Fig. 11 shows the activity diagram of the gibbsite-kaolinite-quartz system as a function of the matric potential of the pore solution. When the internal pressure of the water decreases, the stability domain of kaolinite is extended towards lower aqueous silica contents and $\mathrm{pH}$ values.

The dissolved $\mathrm{SiO}_{2}$ and $\mathrm{Al}$ are exported in the lateritic profile by the weathering of primary minerals such as phlogopite and albite, especially when weathered under anisobaric capillary conditions (the simulation sketch). But these species are partially immobilized at the surface by the precipitation of kaolinite whose stability increases with suction (existing in micropores) under isobaric conditions. Meanwhile, the accumulation of dissolved percolating species (macropores) at the bottom of the profile favors the precipitation of the gibbsite there.

In fact, the present conclusions on the potential role of the capillarity are the same as those already drawn by (Trolard and Tardy, 1987) and (Trolard and Tardy, 1989) with, however, two important advances. First, mineral-solution interactions are incorporated in the capillary model (isobaric/anisobaric conditions) by switching from a treatment based on the activity of water to one using capillary pressure. This paves the way to introduce the mineralogical habits and textures inside the thermodynamic calculations. Second, these interpretations now include the relative volumes of the immobile water and of the percolating water, and confirm that the ratio makes the proposition plausible.

In addition, Gilkes et al. (2003) observed persistent kaolinite horizons at the surface of the weathering profile in the Yilgarn craton (Australia) in spite of the thermodynamic disequilibrium with the solutions present in the regolith. They proposed that the weathering would be delayed by the slow diffusion of ions from the microporosity to the draining macroporosity. The present authors also propose the role of capillarity which should stabilize the kaolinite at the surface (see above). Once again (as concluded in the "desert roses" section), the two explanations are not exclusive from each other. 


\section{Conclusions and outlook}

The first condition to make the capillary thermodynamics (e.g. [Mercury and Tardy, 2001], [Mercury et al., 2003] and [Lassin et al., 2005]) useful is to demonstrate that the volume of capillary water can make up a significant amount of soil water. Using the so-called WRC, extrapolated at high suction with adapted formalism, it was calculated for various soil types that these volumes can reach several tens of $\mathrm{L} / \mathrm{m}^{3}$ of soil, which is consistent with measured values. This capillary aqueous solution interacts with the solid matrix with its own geochemical dynamics defining peculiar solution-solid-gas equilibrium states and so specific mineralogical assemblages in heterogeneous soils.

The practical consequences of the capillary properties of one aqueous solution were tentatively simulated for two different situations using PHREEQC by including thermodynamic data from THERMO-ZNS, considering different scenarios concerning the way minerals equilibrate with capillary solutions:

(i) First, the modification of the stability of the minerals was tested when subjected to arid conditions in sebkha. Capillary properties correctly predict an increase in gypsum precipitation rates, through a mechanism (change of equilibrium constant) able to very strongly increase the growth rate, which is required to enable the (observed) trapping of sand grains inside the gypsum precipitate. It is worth noting that this engulfment is also made easier by the mechanical links constituted by the capillary solution which bridges the sand grains before the precipitation occurs (UZ medium). More generally, capillary bridges could have major consequences on the retention of nanoparticles in microporous systems,

(ii) Second, it was considered if capillarity might account for inverted mineralogical sequences observed in soil profiles weathered from granitic bedrock under very strong climatic condition variations. Results of the simulation show that the capillary approach is coherent with chemical disequilibria observed in natural systems, offering in addition to include the mineral textures in the geochemical modeling. Above all, this frame of reasoning leads to distinguishing the capillary-active microporosity from the percolating macroporosity, which is the matric potential analog of the mobile-immobile zones classically defined in hydraulic conductivity considerations. In terms of mass balance at the soil profile level, the chemical disequilibrium between macro-(free water) and micro-(capillary solution) pores sustains the required gradient for the chemical exchange between the two sub-systems to give the capillarity an impact along the whole soil profile.

The capillary geochemistry coupled to the extension of the WRC at high suction still appears well-suited to modeling mass transfer in hydrogeochemical sub-surface systems. However, the frame now considers a possible disconnection/complementarity between the size of pores and suction, usually related together via the Young-Laplace equation. The way the capillary liquid is stabilized through non-saturated soils is then a new question to be treated with petrophysical constraints. This latter conclusion will be finally extended considering the geomechanical constraints of capillary bridges.

\section{Acknowledgements}

Funding was provided by BRGM (French Geological Survey) through the Research Division Project MODHYC. The careful reviews of Dr. Bertolo and two anonymous reviewers considerably improved the scientific quality and the English spelling of the manuscript. 


\section{References}

Alletto et al., 2006 L. Alletto, Y. Coquet, P. Vachier and C. Labat, Hydraulic conductivity, immobile water content, and exchange coefficient in three soil profiles, Soil Sci. Soc. Am. J. 70 (2006), pp. 1272-1280.

Anand and Paine, 2002 R.R. Anand and M. Paine, Regolith geology of the Yilgarn Craton, Western Australia: implications for exploration, Aust. J. Earth Sci. 49 (2002), pp. 3-162.

Anand et al., 2002 R.R. Anand, M. Paine and R.E. Smith, Genesis, Classification and Atlas of Ferruginous Materials, Yilgarn Craton. CRC LEME Open File Report vol. 13, CSIRO Exploration and Mining, Perth, WA (2002).

Andraski, 1997 B. Andraski, Soil-water movement under natural-site and waste-site conditions: a multiple-year study in the Mojave Desert, Nevada, Water Resour. Res. 33 (1997), pp. 1901-1916

Bourman, 1993 R.P. Bourman, Perennial problems in the study of laterite: a review, Aust. J. Earth Sci. 40 (1993), pp. 387-401.

Brooks and Corey, 1966 R.H. Brooks and A.T. Corey, Properties of porous media affecting fluid flow, J. Irrig. Drain. Div.; Am. Soc. Civil Eng. 92 (1966), pp. 61-88.

Campbell and Shiozawa, 1992 G.S. Campbell and S. Shiozawa, Prediction of hydraulic properties of soils using particle-size distribution and bulk density data. In: M.Th. van Genuchten, F.J. Leij and L.J. Lund, Editors, Proc. Internat. Workshop Indirect Methods for Estimating the Hydraulic Properties of Unsaturated Soils, University of California, Riverside, CA (1992), pp. 317-328.

Caupin and Herbert, 2006 F. Caupin and E. Herbert, Cavitation in water: a review, C. R. Phys. 6 (2006), pp. 1000-1017.

Cornelis et al., 2005 W.M. Cornelis, M. Khlosi, R. Hartmann, M. Van Meirvenne and B. De Vos, Comparison of unimodal analytical expressions for the soil-water retention curves, Soil Sci. Soc. Am. J. 69 (2005), pp. 1902-1911.

Corte, 1962 A.E. Corte, Vertical migration of particles in front of a moving freezing plane, $J$. Geophys. Res. 67 (1962), pp. 1085-1090.

Debenedetti, 1996 P.G. Debenedetti, Metastable Liquids. Concepts and Principles, Princeton University Press (1996).

Duchaufour, 2001 Duchaufour, P., 2001. Introduction à la science du sol. Sol, végétation, environnement, sixth ed. de l'Abrégé de pédologie. Dunod éditions, Sciences de la nature et de la vie, France.

Flint et al., 2002 A.L. Flint, G.S. Campbell, K.M. Ellet and C. Calissendorff, Calibration and temperature correction of heat dissipation matric potential sensors, Soil Sci. Soc. Am. J. 66 (2002), pp. 1439-1445.

Fouillac et al., 1977 C. Fouillac, G. Michard and G. Bocquier, Une méthode de simulation de l'évolution des profils d'altération, Geochim. Cosmochim. Acta 41 (1977), pp. 207-213. 
Fritz, 1975 B. Fritz, Etude thermodynamique et modélisation des réactions entre minéraux et solutions, Application à la géochimie des altérations et des eaux continentale, Strasbourg, Louis Pasteur University (1975).

Furian et al., 2002 S. Furian, L. Barbiéro, R. Boulet, P. Curmi, M. Grimaldi and C. Grimaldi, Distribution and dynamics of gibbsite and kaolinite in an oxisol of Serra do Mar, southeastern Brazil, Geoderma 106 (2002), pp. 83-100.

Gilkes et al., 2003 B. Gilkes, S. Lee and B. Singh, The imprinting of aridity upon a lateritic landscape: an illustration from southwestern Australia, C. R. Geosci. 335 (2003), pp. 12071218.

Hillel et al., 1998 D. Hillel, A.W. Warrick, R.S. Baker and C. Rosenzweig, Environmental Soil Physics, San Diego, Academic Press (1998).

Ishizuka et al., 2005 M. Ishizuka, M. Mikami, Y. Yamada, F. Zeng and W. Gao, An observational study of soil moisture effects on wind erosion at a gobi site in the Taklimakan Desert, J. Geophys. Res. 110 (2005), p. D18S03.

Johnson et al., 1992 J.W. Johnson, E.H. Oelkers and H.C. Helgeson, SUPCRT92: a software package for calculating the standard molar thermodynamic properties of minerals gases and aqueous species from 1 to 5000 bars and $0^{\circ}$ to $1000^{\circ} \mathrm{C}$, Comput. Geosci. 18 (1992), pp. 899947.

Kastner, 1970 M. Kastner, An inclusion hourglass pattern in synthetic gypsum, Am. Mineral. 55 (1970), pp. 2128-2130.

Kew and Gilkes, 2006 G. Kew and R. Gilkes, Classification, strength and water retention characteristics of lateritic regolith, Geoderma 136 (2006), pp. 184-198.

Köhne et al., 2004 J.M. Köhne, S. Köhne, B.P. Mohanty and J. Šimůnek, Inverse mobileimmobile modeling of transport during transient flow: effects of between-domain transfer and initial water content, Vadose Zone J. 3 (2004), pp. 1309-1321.

Krönberg et al., 1982 B. Krönberg, W. Fyfe, B. Mc Kinnon, J. Couston, B. Stilianidi Filho and R. Nash, Model for bauxite formation: paragominas (Brazil), Chem. Geol. 35 (1982), pp. $311-320$.

Kuechler et al., 2004 R. Kuechler, K. Noack and T. Zorn, Investigation of gypsum dissolution under saturated and unsaturated water conditions, Ecol. Model. 176 (2004), pp. 1-14.

Lasaga, 1998 A.C. Lasaga, Kinetic Theory in the Earth Sciences, Princeton University Press, Princeton (1998).

Lassin et al., 2003 Lassin, A., Pinault, J.-L., Azaroual, M., 2003. Thermodynamique de la zone non saturée en eau des systèmes géologiques. BRGM/RP-52010-FR. 
Lassin et al., 2005 A. Lassin, M. Azaroual and L. Mercury, Geochemistry of unsaturated soil systems: aqueous speciation and solubility of minerals and gases in capillary solutions, Geochim. Cosmochim. Acta 69 (2005), pp. 5187-5201.

Low, 1961 P.F. Low, Physical chemistry of clay-water interactions, Adv. Agron. 13 (1961), pp. 269-327.

Lucas et al., 1996 Y. Lucas, D. Nahon, S. Cornu and F. Eyrolle, Genèse et fonctionnement des sols en milieu equatorial, C. R. Acad. Sci. Paris 322 (1996), pp. 1-16.

Mathias et al., 2006 S.A. Mathias, A.P. Butler, B.M. Jackson and H.S. Wheater, Transient simulations of flow and transport in the chalk unsaturated zone, J. Hydrol. 330 (2006), pp. $10-28$.

McCrea et al., 1990 A.F. McCrea, R.R. Anand and R.J. Gilkes, Mineralogical and physical properties of lateritic pallid zone materials developed from granite and dolerite, Geoderma 47 (1990), pp. 33-57.

Mehta et al., 1994 B.K. Mehta, S. Shiozawa and M. Nakano, Hydraulic properties of a sandy soil at low water contents, Soil Sci. 157 (1994), pp. 208-214.

Mercury and Tardy, 1997a L. Mercury and Y. Tardy, Negative pressure and thermodynamic properties of capillary water, C. R. Acad. Sci. Paris 324 (11) (1997), pp. 863-873.

Mercury and Tardy, 1997b L. Mercury and Y. Tardy, Physicochemical features of water in capillaries and fog water droplets, C. R. Acad. Sci. Paris 325 (12) (1997), pp. 947-954.

Mercury and Tardy, 2001 L. Mercury and Y. Tardy, Negative pressure of stretched liquid water. Geochemistry of soil capillaries, Geochim. Cosmochim. Acta 65 (2001), pp. 3391-3408

Mercury and Tardy, 2004 L. Mercury and Y. Tardy, Response to the Comment by J.V. Walther on: "Negative pressure of stretched liquid water. Geochemistry of soil capillaries". and "Thermodynamic properties of solutions in metastable systems under negative or positive pressures”, Geochim. Cosmochim. Acta 68 (2004), pp. 2775-2780.

Mercury et al., 2003 L. Mercury, M. Azaroual, H. Zeyen and Y. Tardy, Thermodynamic properties of solutions in metastable systems under negative or positive pressure, Geochim. Cosmochim. Acta 67 (2003), pp. 1769-1785.

Mercury et al., 2004 L. Mercury, D. Pinti and H. Zeyen, The effect of the negative pressure of capillary water on atmospheric noble gas solubility in ground water and palaeotemperature reconstruction, Earth Planet. Sci. Lett. 223 (2004), pp. 147-161.

Morel-Seytoux and Nimmo, 1999 H.J. Morel-Seytoux and J.R. Nimmo, Soil water retention and maximum capillary drive from saturation to oven dryness, Water Resour. Res. 35 (1999), pp. 2031-2041.

Mutakyahwa et al., 2003 M. Mutakyahwa, J. Ikingura and A. Mruma, Geology and geochemistry of bauxite deposits in Lushoto District, Usambara Mountains, Tanzania, J. Afr. Earth Sci. 36 (2003), pp. 357-369. 
Parkhurst and Appelo, 1999 D.L. Parkhurst and C.A.J. Appelo, User's guide to PHREEQC (version 2) - a computer program for speciation, batch-reaction, one dimensional transport, and inverse geochemical calculation, US Geol. Surv. Water-Resour. Invest. Rep. (1999), pp. 99-4259.

Prunty and Casey, 2002 L. Prunty and F.X.M. Casey, Soil water retention curve description using a flexible smooth function, Vadose Zone J. 1 (2002), pp. 179-185.

Putnis et al., 1995 A. Putnis, M. Prieto and L. Fernandez-Diaz, Fluid supersaturation and crystallization in porous media, Geol. Mag. 132 (1995), pp. 1-13.

Roedder, 1967 E. Roedder, Metastable superheated ice in liquid-water inclusions under high negative pressure, Science 155 (1967), pp. 1413-1417.

Ross et al., 1991 P.J. Ross, J. Williams and K.L. Bristow, Equation for extending waterretention curves to dryness, Soil Sci. Soc. Am. J. 55 (1991), pp. 923-927.

Rossi and Nimmo, 1994 C. Rossi and J.R. Nimmo, Modeling of soil water retention from saturation to oven dryness, Water Resour. Res. 30 (1994), pp. 701-708.

Scanlon et al., 2003 B.R. Scanlon, K. Keese, R.C. Reedy, J. Šimůnek and B.J. Andraski, Variations in flow and transport in thick desert vadose zones in response to paleoclimatic forcing (0-90 kyr): field measurements, modeling, and uncertainties, Water Resour. Res. 39 (2003), p. 1179.

Scherer, 1999 G.W. Scherer, Crystallization in pores, Cem. Concr. Res. 29 (1999), pp. 13471358.

Scholander et al., 1965 P.F. Scholander, H.T. Hammel, E.D. Bradstreet and E.A.

Hemmingsen, Sap pressure in vascular plants. Negative hydrostatic pressure can be measured in plants, Science 148 (1965), pp. 339-346.

Shearman, 1981 D.J. Shearman, Displacement of sand grains in sandy gypsum cristals, Geol. Mag. 118 (1981), pp. 303-306.

Span and Wagner, 2000 Span, R., Wagner, W., 2000. Das Software-Grundpaket zur Berechnung thermodynamischer Daten in Referenzqualität. Ruhr-Universität Bochum Report.

Stockwell et al., 2006 J. Stockwell, L. Smith, J.L. Jambor and R. Beckie, The relationship between fluid flow and mineral weathering in heterogeneous unsaturated porous media: a physical and geochemical characterization of a waste-rock pile, Appl. Geochem. 21 (2006), pp. 1347-1361.

Tamari et al., 1993 S. Tamari, J.-C. Gaudu and T. Simonneau, Tensiometric measurement and metastable state of water under tension, Soil Sci. 156 (1993), pp. 149-155.

Tanger and Helgeson, 1988 J.C. Tanger and H.C. Helgeson, Calculation of the thermodynamic and transport properties of aqueous species at high pressures and temperatures: revised equations of state for the standard partial molal properties of ions and electrolytes, Am. J. Sci. 288 (1988), pp. 19-98. 
Tardy and Nahon, 1985 Y. Tardy and D. Nahon, Geochemistry of laterites, stability of AlGoethite, Al-Hematite, and $\mathrm{Fe}^{3+}$-Kaolinite in bauxites and ferricretes: an approach to the mechanism of concretion formation, Am. J. Sci. 285 (1985), pp. 865-903.

Tardy and Novikoff, 1988 Y. Tardy and A. Novikoff, Activité de l'eau et déplacement des équilibres gibbsite-kaolinite dans les profils latéritiques, C. R. Acad. Sci. Paris 306 (1988), pp. 39-44.

Trolard and Tardy, 1987 F. Trolard and Y. Tardy, The stabilities of gibbsite, boehmite, aluminous goethites and aluminous hematites in bauxites, ferricretes and laterites as a function of water activity, temperature and particle size, Geochim. Cosmochim. Acta $\mathbf{5 1}$ (1987), pp. 945-957.

Trolard and Tardy, $1989 \mathrm{~F}$. Trolard and Y. Tardy, A model of $\mathrm{Fe}^{3+}$-kaolinite, $\mathrm{Al}^{3+}$-goethite, $\mathrm{Al}^{3+}$-hematite equilibria in laterites, Clay Min. 24 (1989), pp. 1-21.

Tyree and Zimmermann, 2002 M.T. Tyree and M.H. Zimmermann, Xylem Structure and the Ascent of Sap (second ed.), Springer Verlag (2002).

van Genuchten, 1980 M. van Genuchten, A closed form equation for predicting the hydraulic conductivity of unsaturated soils, Soil Sci. Soc. Am. J. 44 (1980), pp. 892-898.

White et al., 1998 A.F. White, A.E. Blum, M.S. Schulz, D.V. Vivit, D.A. Stonestrom, M. Larsen, S.F. Murphy and D. Eberl, Chemical weathering in a tropical watershed, Luquillo Mountains, Puerto Rico: I. Long-term versus short-term weathering fluxes, Geochim. Cosmochim. Acta 62 (1998), pp. 209-226.

Wu and Nancollas, 1999 W. Wu and G.H. Nancollas, Determination of interfacial tension from crystallization and dissolution data: a comparison with other methods, Adv. Colloid Interface. Sci. 79 (1999), pp. 229-279.

Zheng et al., 1991 Q. Zheng, D.J. Durben, G.H. Wolf and C.A. Angell, Liquids at large negative pressures: water at the homogeneous nucleation limit, Science 254 (1991), pp. 829832. 


\section{Appendix A}

The Rossi-Nimmo junction model (1994) associates a strength function $\left(\theta_{\mathrm{I}}\right)$ describing the relationship at low suction with a logarithmic function $\left(\theta_{\mathrm{II}}\right)$ adapted to higher suctions.

The conditions ensuring the continuity of these equations described in Table 1 are

$\underline{\theta}_{\underline{I}}\left(\Psi_{\mathrm{i}}\right)=\theta_{\underline{I I}}\left(\Psi_{\mathrm{i}}\right)$

and

$\frac{\partial \theta_{i}}{\partial \Psi}\left(\Psi_{i}\right)=\frac{\partial \theta_{n}}{\partial \Psi}\left(\Psi_{i}\right)$

$\underline{\theta}_{\text {II }}\left(\Psi_{\mathrm{j}}\right)=\theta_{\text {III }}\left(\Psi_{\mathrm{i}}\right)$

and

$\frac{\partial \theta_{\mathbf{I}}}{\partial \Psi}\left(\Psi_{\mathbf{i}}\right)=\frac{\partial \theta_{\mathbf{m}}}{\partial \Psi}\left(\Psi_{i}\right)$

The solving of continuity Eqs. (a), (b), (c) and (d) by replacing $\theta_{\mathrm{I}}, \theta_{\mathrm{II}}$, and $\theta_{\mathrm{III}}$ by Eqs. (I)-(III) of the following table enable the expression of analytical functions $\alpha_{\mathrm{RN}}, c, \Psi_{\mathrm{i}}$, and $\Psi_{\mathrm{j}}$ as a function of measurable parameters $\Psi_{\mathrm{e}}$ and $\lambda$ (Eqs. (e), (f), (g) and (h)).

$$
\begin{aligned}
& \Psi_{i}=\Psi_{a}\left(\frac{2}{2}+1\right)^{\frac{1}{2}} \\
& \Psi_{\mathrm{j}}=\exp \left(\ln \Psi_{\mathrm{B}}-\frac{1}{2}\right) \\
& c=\frac{1-\left(\frac{p_{\mathrm{c}}}{\mathrm{F}_{i}}\right)^{3}}{\left(\frac{\gamma_{i}}{y_{\mathrm{c}}}\right)^{2}} \\
& \alpha_{\mathrm{RN}}=\lambda \Psi_{\mathrm{q}}^{2} \Psi_{\mathrm{i}}^{-L}
\end{aligned}
$$


Synthesis of the parameters required to model the retention curves according to the RossiNimmo junction model (1994).

\begin{tabular}{|l|l|}
\hline Parameters & Junction model \\
\hline$\Psi_{\mathrm{e}}$ & Air-entry pressure $(\mathrm{cm})$ \\
\hline$\Psi_{\mathrm{m}}$ & Matric potential $(\mathrm{cm})$ \\
\hline$\Psi_{\mathrm{D}}$ & Total potential at the oven-dry conditions \\
\hline$\theta$ & Water content $\left(\mathrm{cm}^{3} \mathrm{~cm}^{-3}\right)$ \\
\hline$\theta_{\mathrm{s}}$ & Water content at saturation $\left(\mathrm{cm}^{3} \mathrm{~cm}^{-3}\right)$ \\
\hline$\lambda$ & Poral distribution index \\
\hline$\underline{\theta_{\mathrm{I}}=\theta / \theta_{\underline{S}}}$ & Relative water content at $0<\Psi_{\mathrm{m}}<\Psi_{\mathrm{i}}$ \\
\hline
\end{tabular}

$\theta_{1}=1-c\left(\frac{\Psi_{i}}{\Psi_{0}}\right)^{2}$

Relative water content at $\Psi_{\mathrm{i}}<\Psi_{\mathrm{m}}<\Psi_{\mathrm{j}}$

$\underline{\theta}_{\mathrm{II}}=\underline{\theta} \underline{\theta}_{\underline{\underline{S}}} \theta_{\mathrm{UI}}=\left(\frac{\Psi_{Q}}{\Psi_{\mathrm{m}}}\right)^{2}$

Relative water content at $\Psi_{\mathrm{j}}<\Psi_{\mathrm{m}}<\Psi_{\mathrm{D}}$

$\underline{\theta}_{\underline{I I}}=\theta / \theta_{\underline{s}} \quad \theta_{\mathrm{MI}}=\alpha \ln \left(\frac{\Psi_{\mathbf{D}}}{\Psi_{\mathbf{m}}}\right)$

$\alpha, c$ Analytical functions with $\Psi_{\mathrm{e}}, \Psi_{\mathrm{i}}$, and $\lambda$ 


\section{Figures}

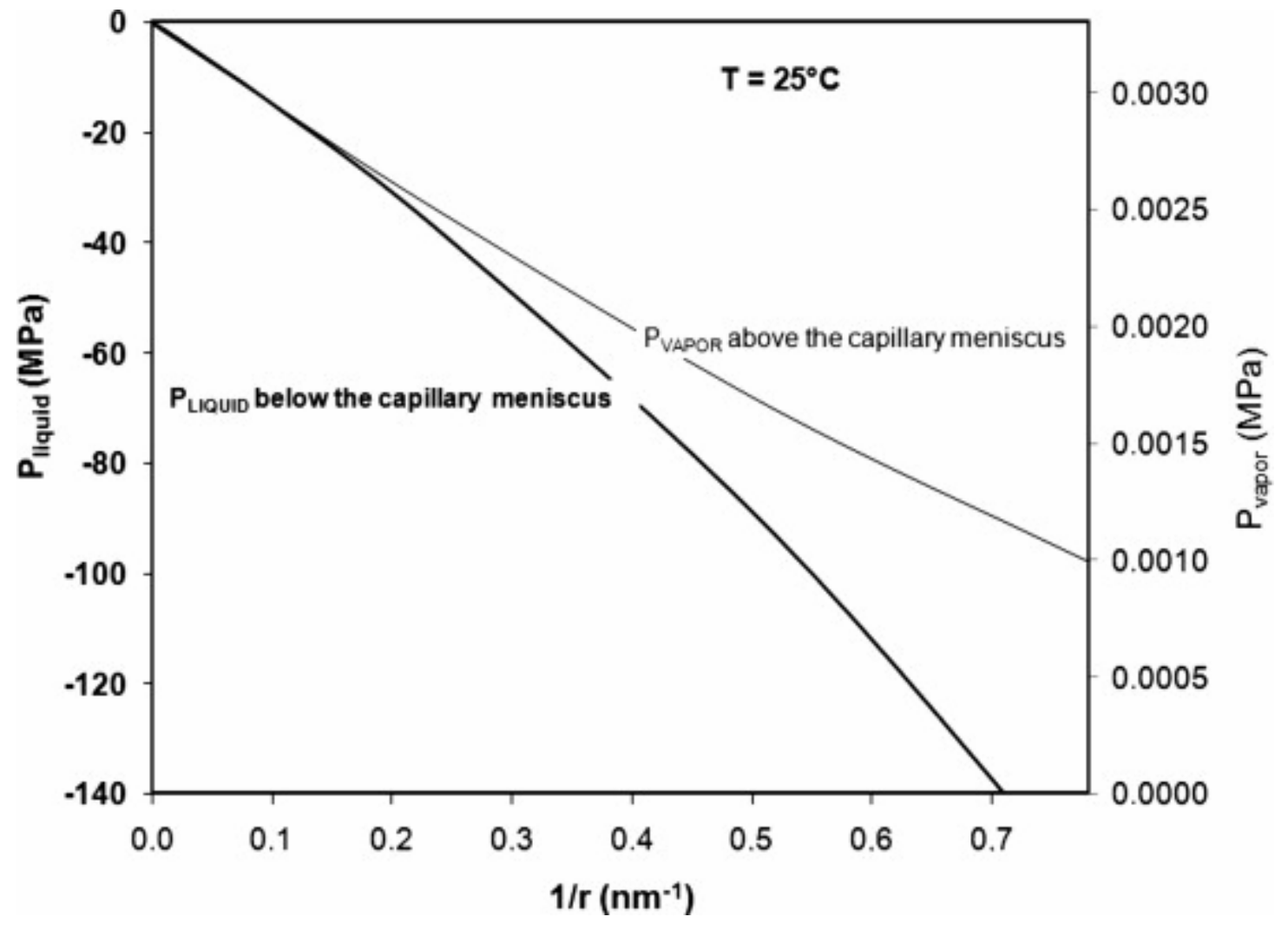

Fig. 1. Vapor and liquid pressures at Young-Laplace equilibrium as a function of liquid-air interface radius $r$ (from plane to highly concave interface), at $25^{\circ} \mathrm{C}$.

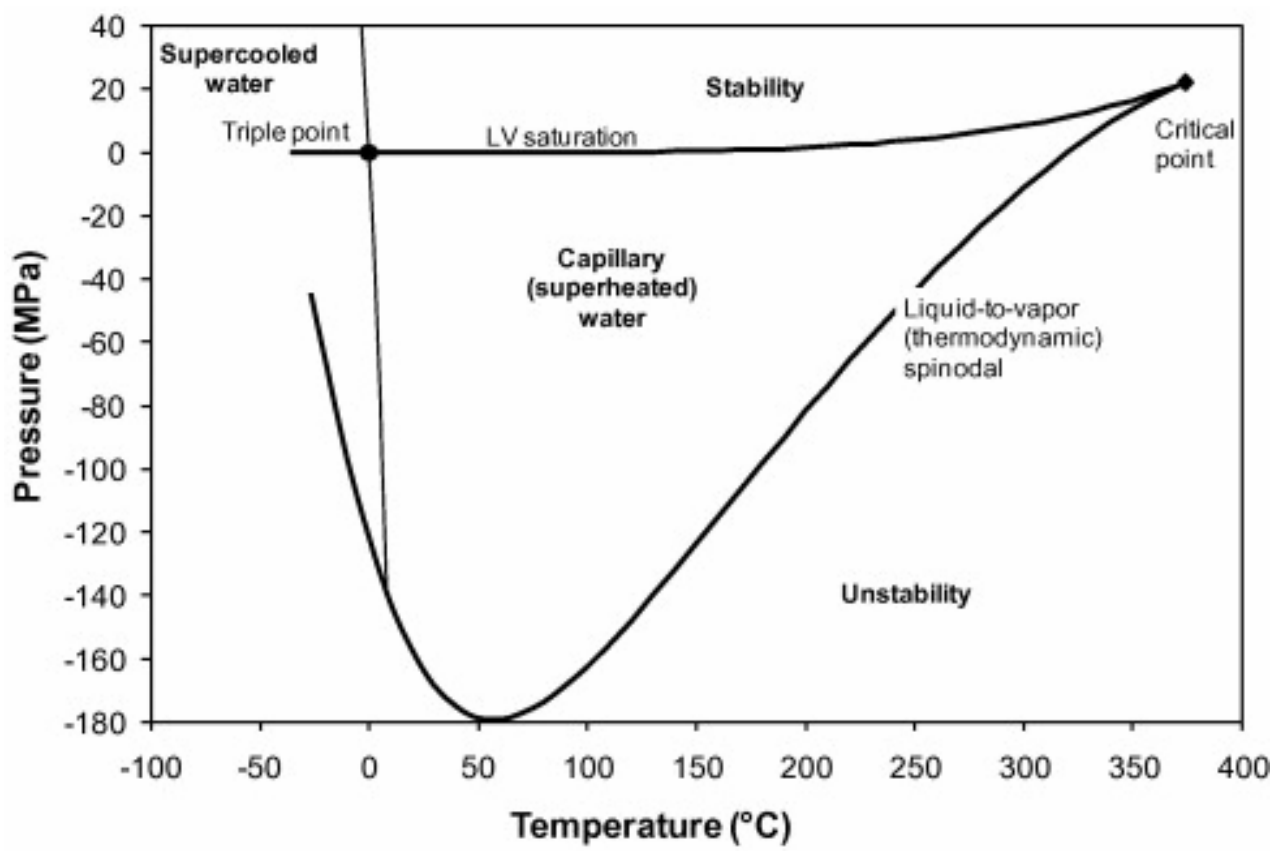

Fig. 2. $P-T$ phase diagram of pure water including its extension to the metastable domain. 


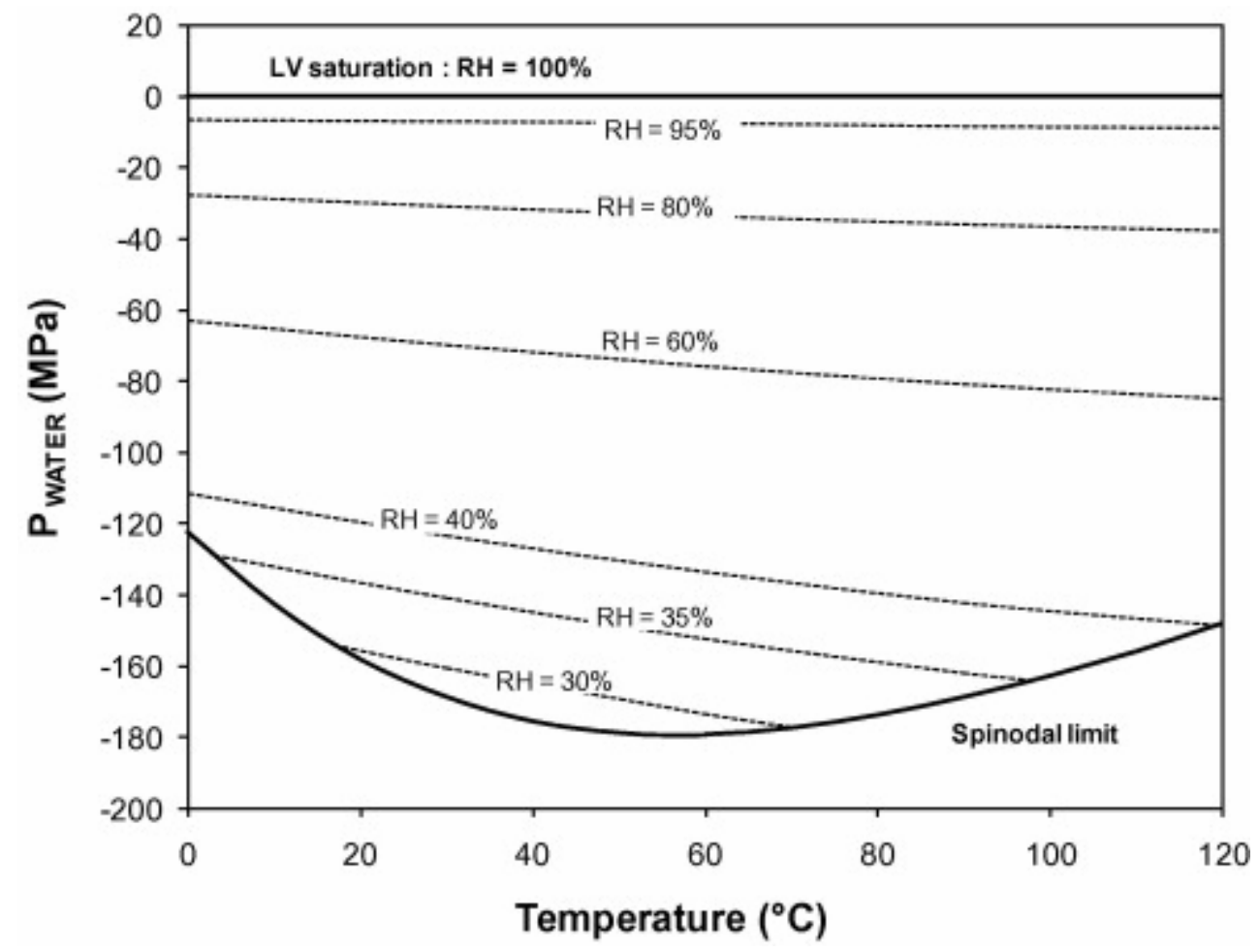

Fig. 3. Internal pressure of capillary water as a function of relative humidity along the metastable superheated liquid domain.

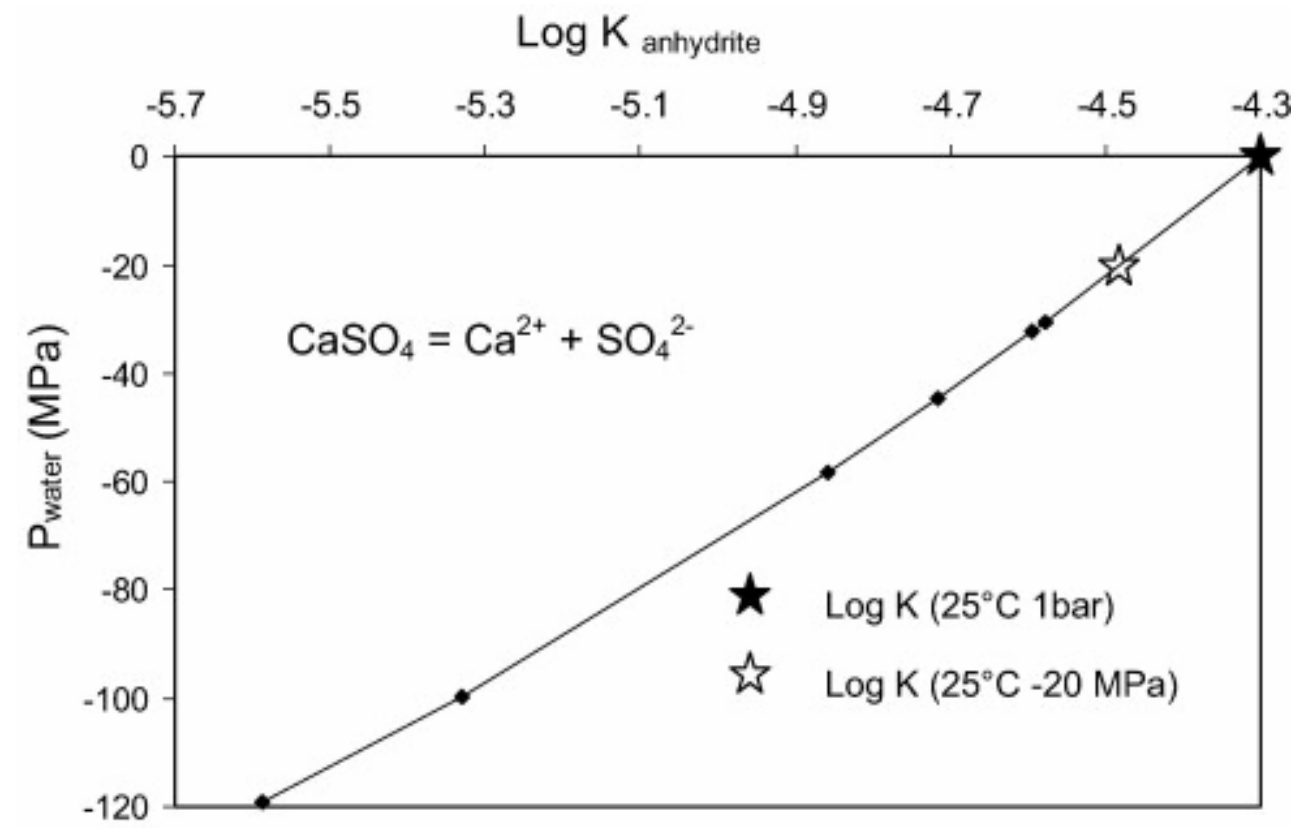

Fig. 4. Anhydrite thermodynamic equilibrium constant as a function of matric potential and pressure conditions. 


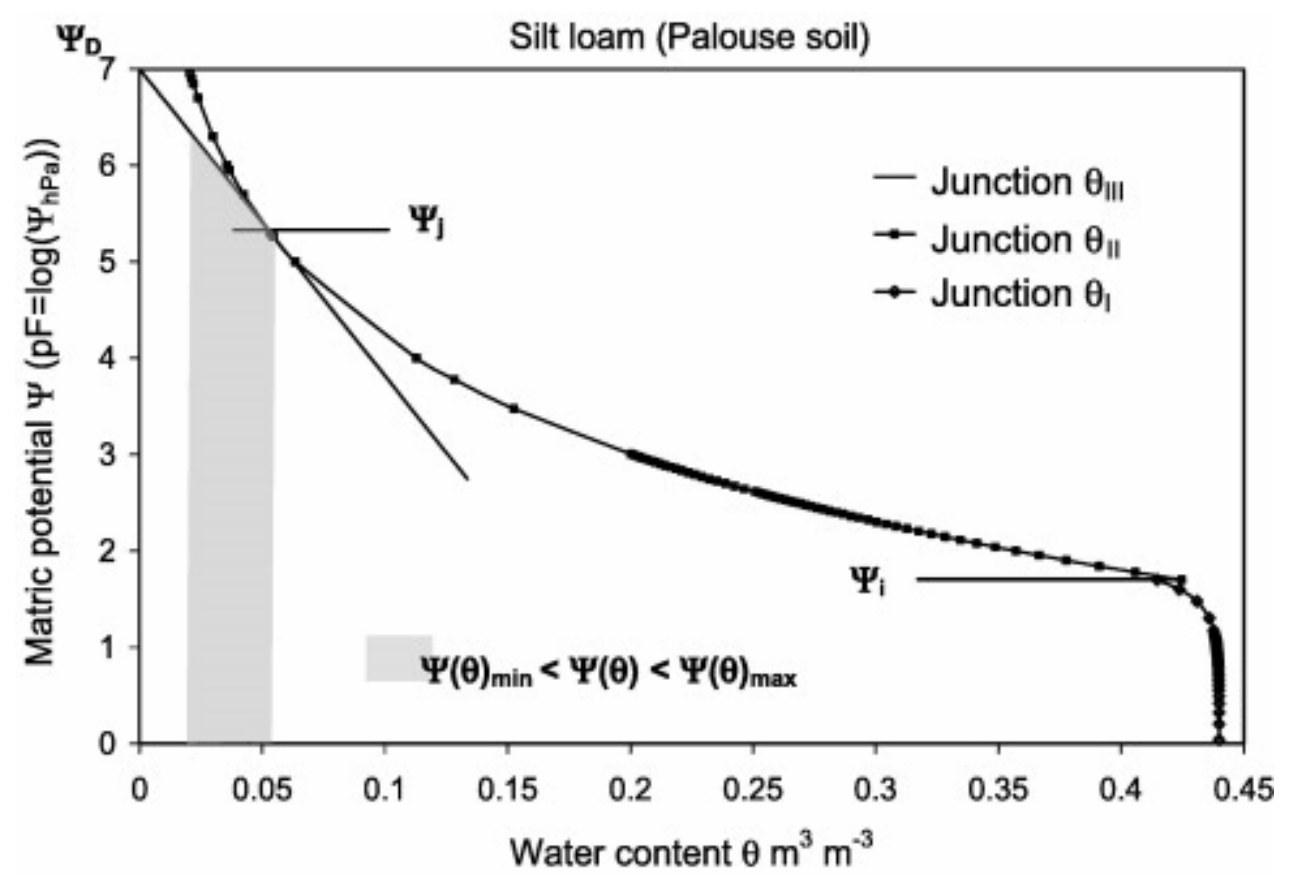

Fig. 5. Retention curve for silt loam soil (junction model, Rossi and Nimmo, 1994)

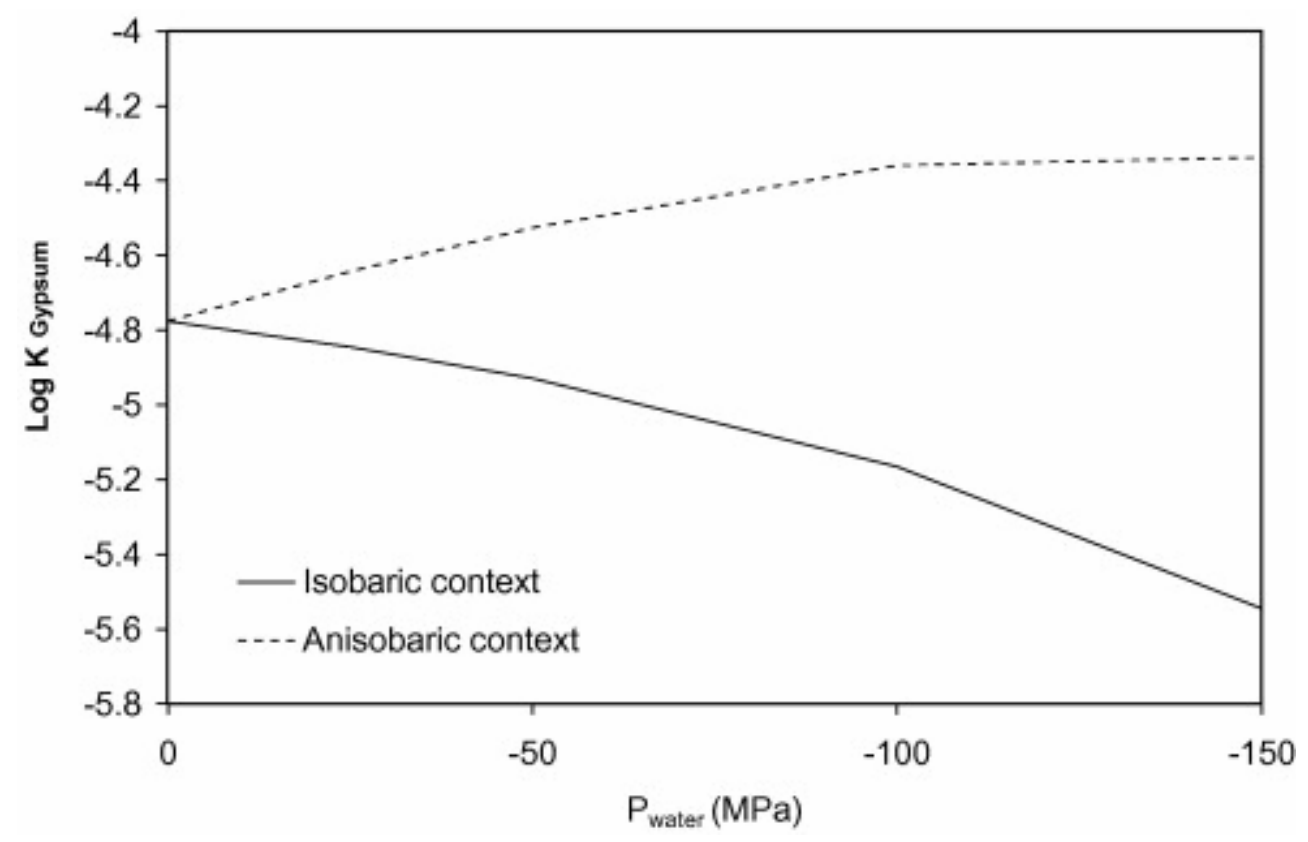

Fig. 6. Gypsum thermodynamic equilibrium constant at $25{ }^{\circ} \mathrm{C}$ as a function of solution pressure and pressure conditions. 

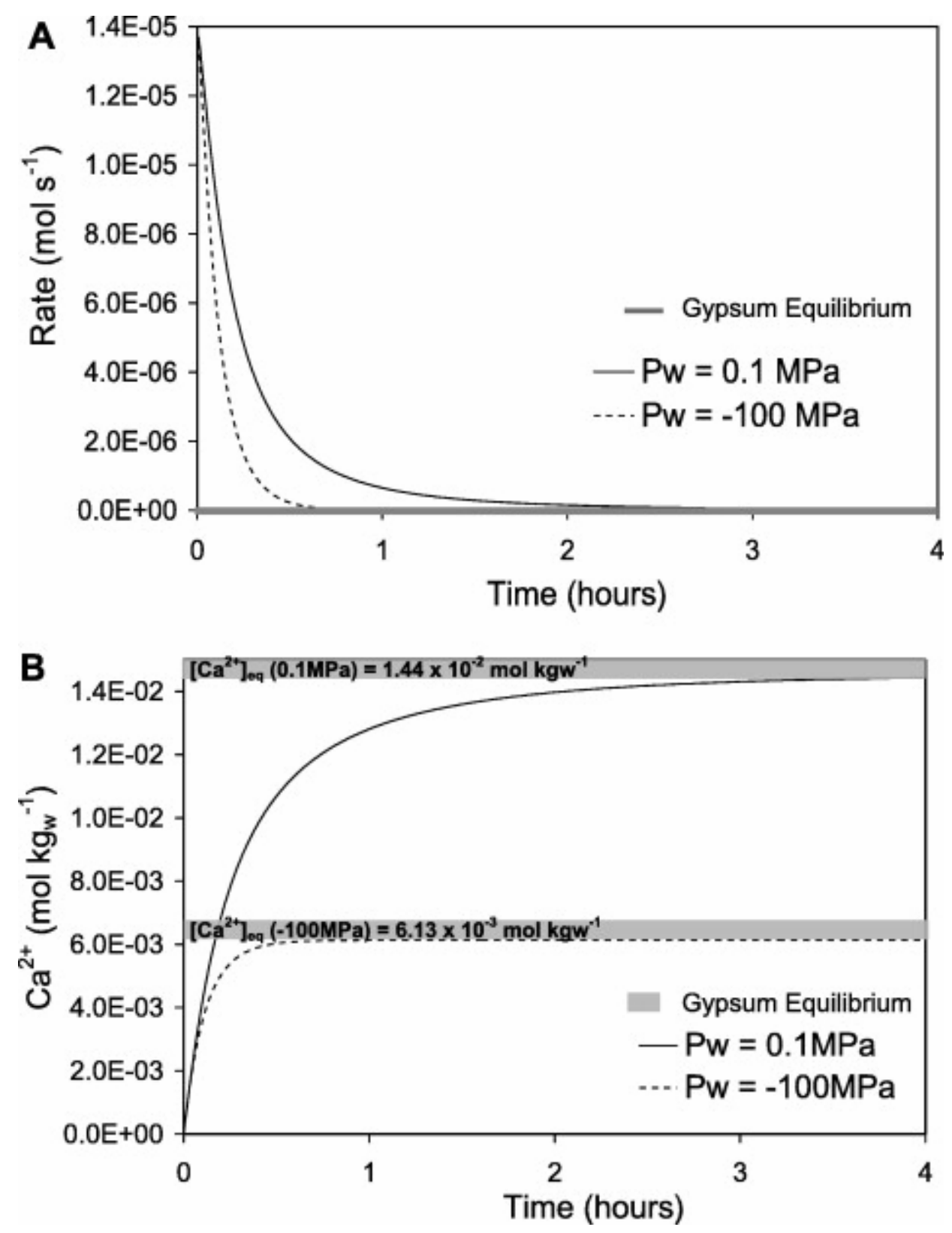

Fig. 7. (A) Gypsum reaction rate $\left(\mathrm{mol} \mathrm{s}^{-1}\right)$ at $25^{\circ} \mathrm{C}$ for a solution under $-100 \mathrm{MPa}$ of pressure and isobaric conditions and under a standard pressure of $0.1 \mathrm{MPa}$. (B) Calcium concentration, from gypsum dissolution, vs. time. 


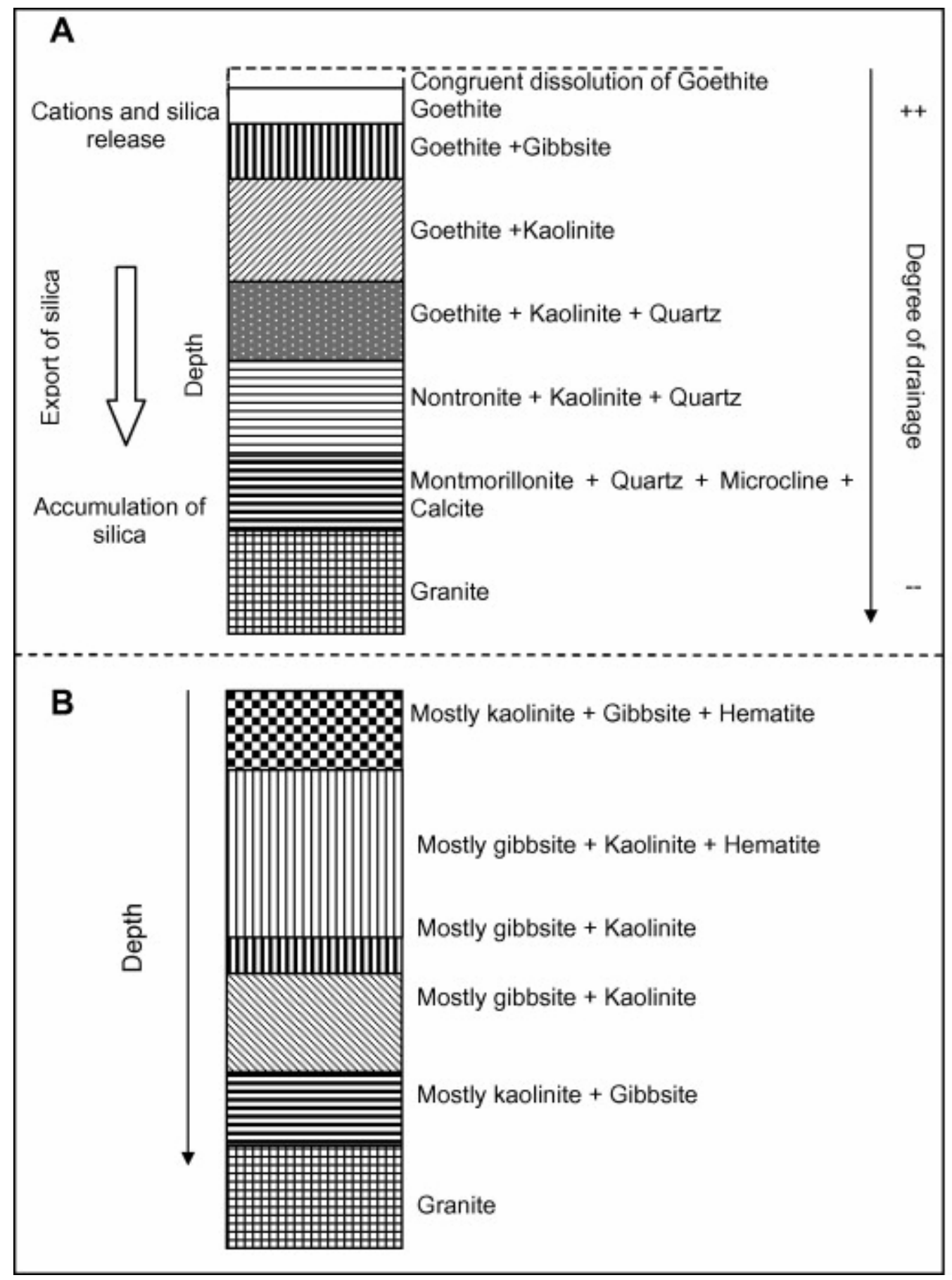

Fig. 8. (A) Theoretical layering of the horizons formed during the simulation of weathering of granite for a water activity of one and a temperature of $25^{\circ} \mathrm{C}$ (from Fritz, 1975). This weathering profile is considered to be "normal". (B) Layering of the horizons from the weathering of granite observed in the Sierra do Mar region (Brazil) (from Furian et al., 2002). This weathering profile is considered to be "abnormal". 

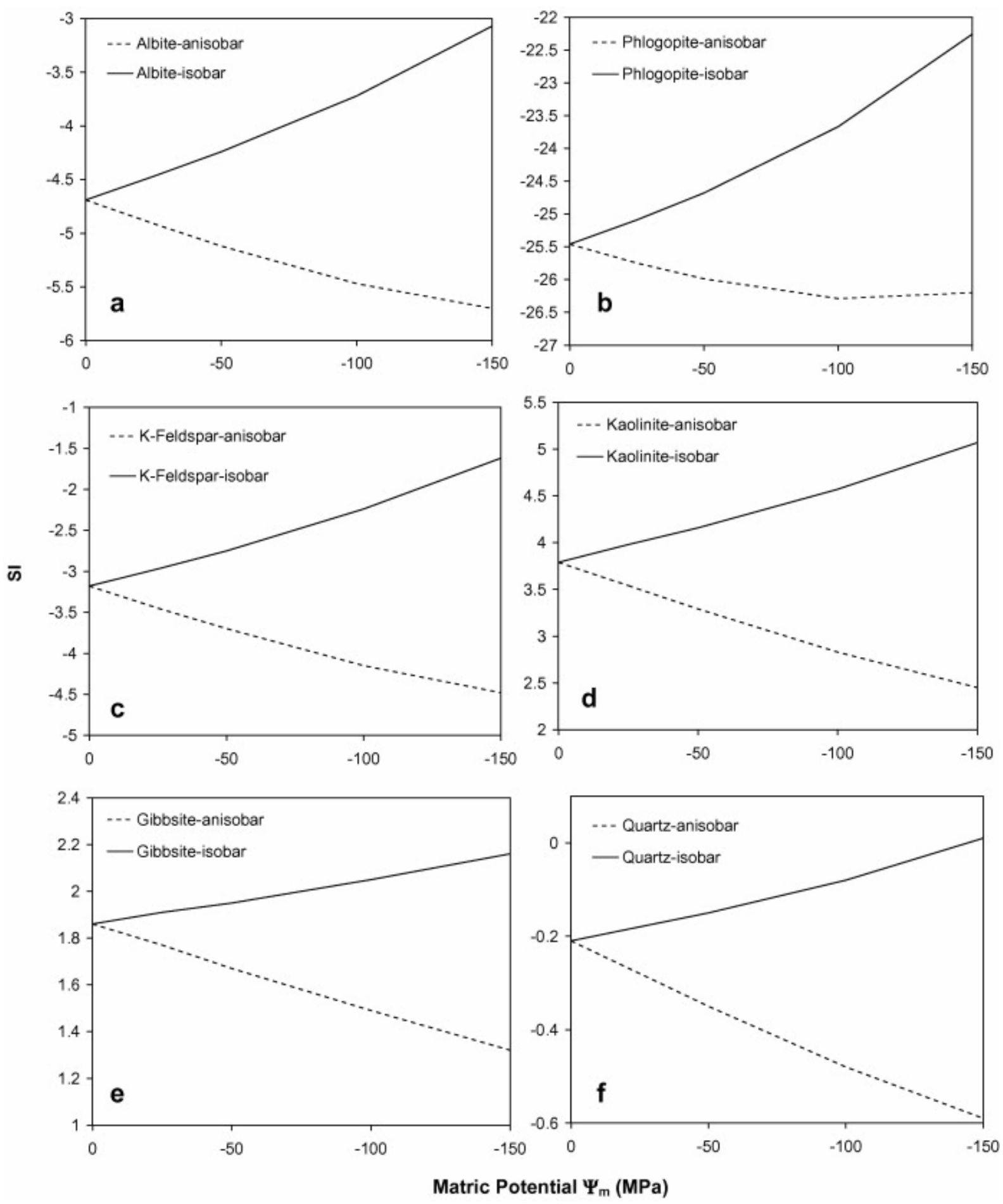

Fig. 9. Saturation indexes for albite, phlogopite, kaolinite, K-feldspar, gibbsite, and quartz as a function of suction, calculated with PHREEQC and THERMO-ZNS for various suctions imposed on the pore solution. 

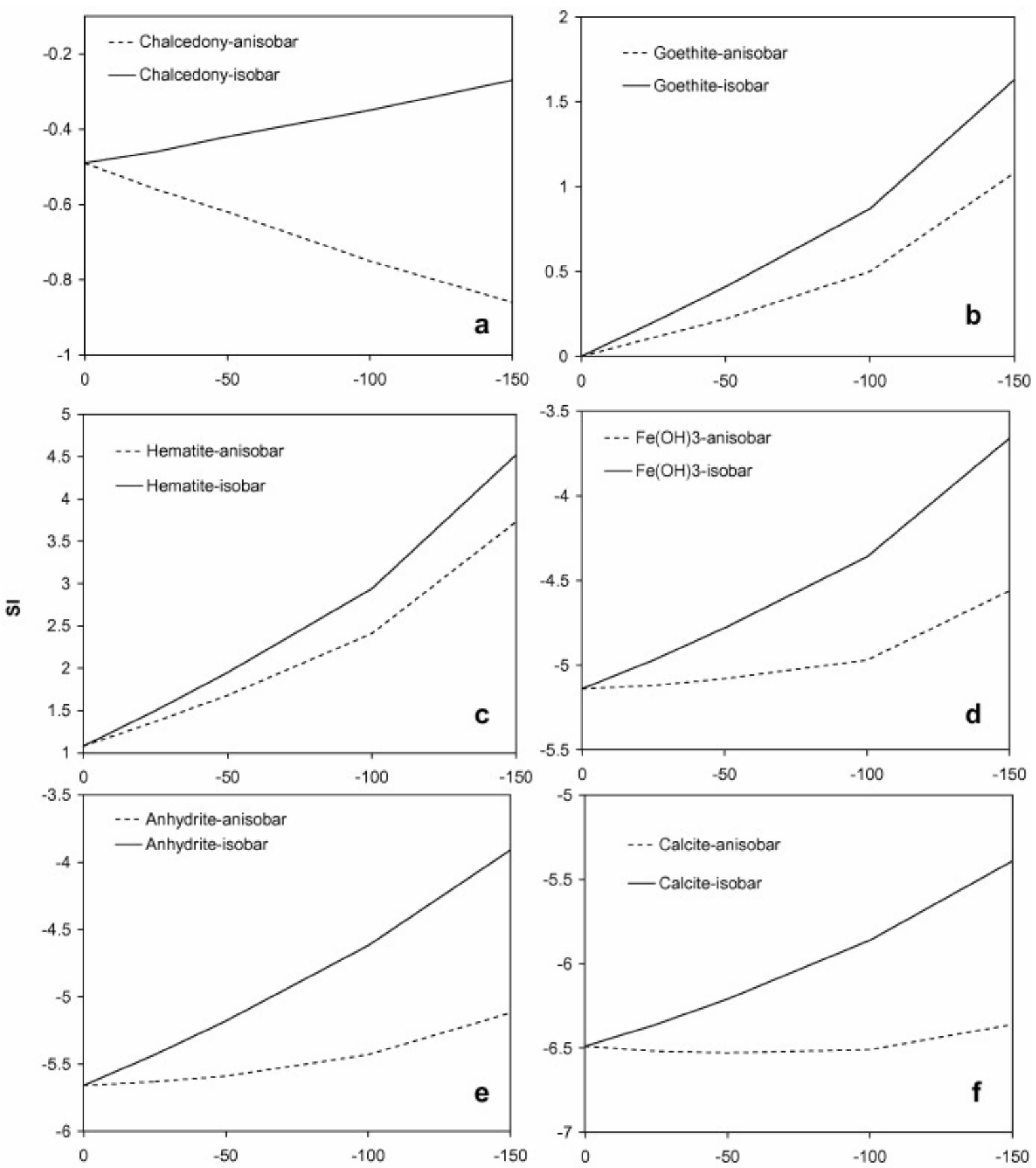

Matric Potentiel $\Psi_{\mathrm{m}}$ (MPa)

Fig. 10. Saturation indexes for Fe hydroxides, chalcedony, calcite, and anhydrite as a function of matric potential. 


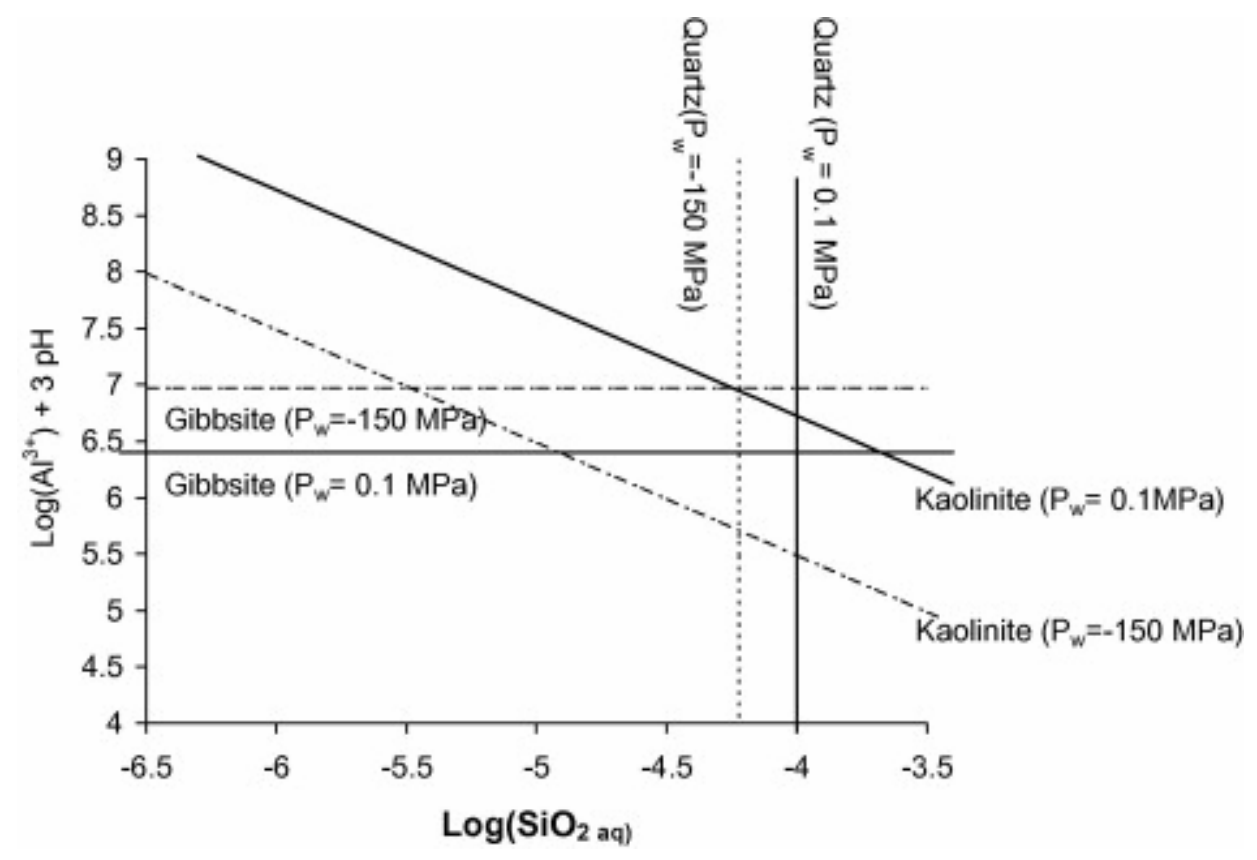

Fig. 11. Activity diagram, $\log \left(\mathrm{Al}^{3+}\right)+3 \mathrm{pH}=\log \left(\mathrm{SiO}_{2}(\mathrm{aq})\right)$, for the kaolinite-quartz-gibbsite stability domains as a function of the matric potential $\Psi_{\mathrm{m}}$.

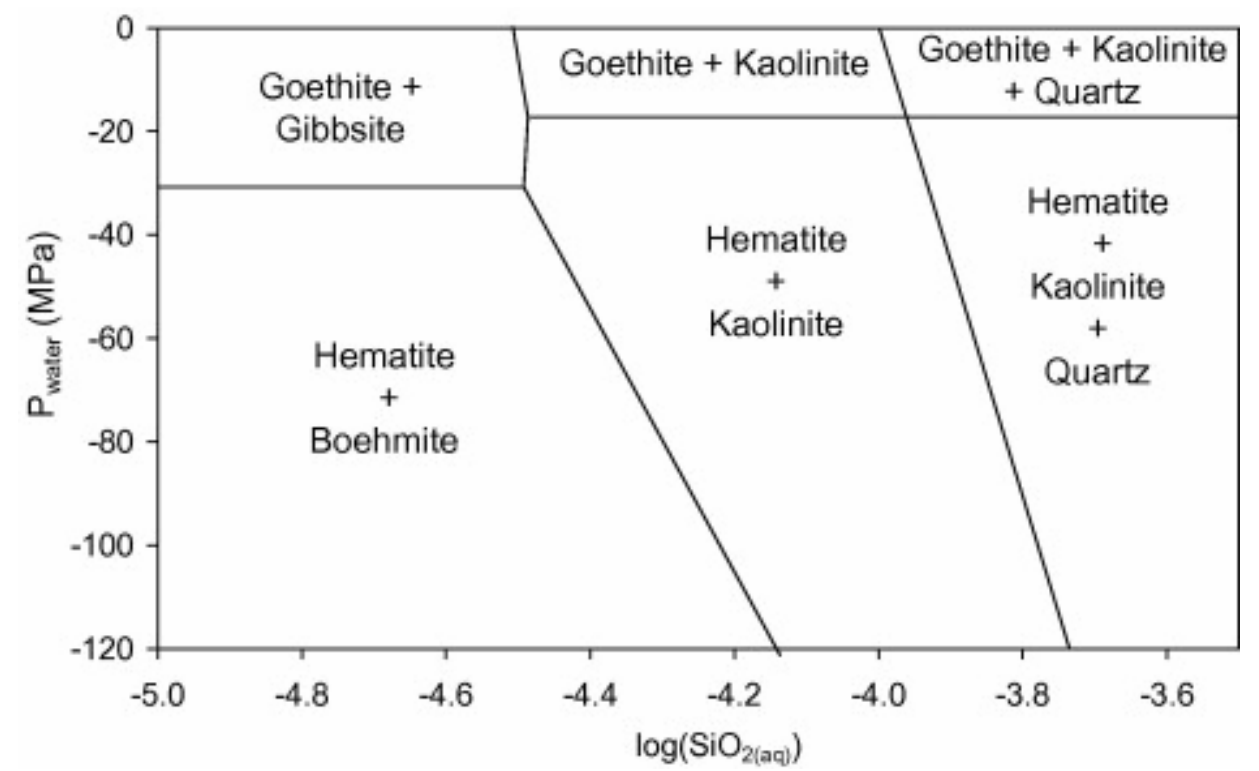

Fig. 12. Stability domains of minerals in the $\mathrm{Fe}_{2} \mathrm{O}_{3}-\mathrm{Al}_{2} \mathrm{O}_{3}-\mathrm{SiO}_{2}-\mathrm{H}_{2} \mathrm{O}$ system as a function of aqueous silica activity and capillary pressure. 


\section{Tables}

Table 1. : Equation parameters required to model the retention curves (WRC).

\begin{tabular}{|l|l|l|l|l|l|l|l|l|}
\hline $\begin{array}{l}\text { Palouse silt } \\
\text { loam }\end{array}$ & $\lambda^{\mathbf{a}}$ & $\boldsymbol{\alpha}^{\mathbf{b}}\left(\mathbf{c m}^{-\mathbf{1}}\right)$ & $\boldsymbol{c}^{\mathbf{b}}$ & $\begin{array}{l}\boldsymbol{\theta}_{\mathbf{s}}^{\mathbf{a}} \\
\left.\mathbf{( c m}^{\mathbf{3}} \mathbf{c m}^{-\mathbf{3}}\right)\end{array}$ & $\begin{array}{l}\boldsymbol{\Psi}_{\mathbf{i}}^{\mathbf{b}} \\
(\mathbf{c m})\end{array}$ & $\begin{array}{l}\boldsymbol{\Psi}_{\mathbf{D}}^{\mathbf{a}} \\
(\mathbf{c m})\end{array}$ & $\begin{array}{l}\boldsymbol{\Psi}_{\mathbf{a}}^{\mathbf{a}} \\
(\mathbf{c m})\end{array}$ & $\boldsymbol{\Psi}_{\mathbf{j}}^{\mathbf{a}}(\mathbf{c m})$ \\
\hline $\begin{array}{l}\text { Junction } \\
\text { model }\end{array}$ & 0.25 & 0.031 & 0.043 & 0.44 & 69.5 & $1 \mathrm{E}+07$ & 43.4 & 183156.4 \\
\hline
\end{tabular}

${ }^{\text {a }}$ Rossi and Nimmo (1994).

${ }^{b}$ This work.

Table 2. : Water volume at $\Psi_{\min }$ and $\Psi_{\max }$ suctions, capillary water content $\theta_{\text {capillary }}$ at high suction.

\begin{tabular}{|l|l|l|l|}
\hline Soil type & $\boldsymbol{\theta}\left(\Psi_{\max }\right)\left(\mathbf{L} / \mathbf{m}^{-3}\right)$ & $\boldsymbol{\theta}\left(\Psi_{\max }\right)\left(\mathbf{L} / \mathbf{m}^{-3}\right)$ & $\boldsymbol{\theta}$ capillary $\left(\mathbf{L} / \mathbf{m}^{-3}\right)$ \\
\hline Silt loam Salkum & 57.3 & 23.4 & 33.9 \\
\hline Silt loam Palouse & 53.3 & 21.9 & 31.4 \\
\hline Sandy loam royal & 12 & 4.3 & 7.7 \\
\hline Sand L-soil & 7.5 & 2.9 & 4.6 \\
\hline
\end{tabular}

Table 3. : Chemical analysis of the annual pore water in $\mu \mathrm{M}$ except $\mathrm{pH}$ (e.g. White et al., 1998) and pe value calculated according to the stability conditions of iron oxides and oxyhydroxides.

\begin{tabular}{|l|l|}
\hline $\mathrm{pH}$ & 4.9 \\
\hline $\mathrm{pe}$ & 15.7 \\
\hline $\mathrm{Na}$ & 204.0 \\
\hline $\mathrm{K}$ & 6.0 \\
\hline $\mathrm{Ca}$ & 12.1 \\
\hline $\mathrm{Mg}$ & 24.4 \\
\hline $\mathrm{Al}$ & 3.4 \\
\hline $\mathrm{SiO}$ & \\
\hline $\mathrm{Alkalinity}\left(\mathrm{HCO}_{3}{ }^{-}\right)$ & 16.4 \\
\hline $\mathrm{Cl}^{-}$ & 246.0 \\
\hline $\mathrm{SO}_{4}$ & 11.0 \\
\hline $\mathrm{Fe}$ & 0.2 \\
\hline
\end{tabular}


Table 4. : Equilibrium reactions of minerals and $\log K\left(25^{\circ} \mathrm{C}, P\right)$ existing in saprolite.

\begin{tabular}{|c|c|c|c|c|c|}
\hline \multirow[t]{2}{*}{ Minerals } & \multicolumn{5}{|c|}{ Reactions and $\log K\left(25^{\circ} \mathrm{C}, P\right)$ calculated with THERMO-ZNS } \\
\hline & $-150 \mathrm{MPa}$ & $-100 \mathrm{MPa}$ & $-50 \mathrm{MPa}$ & $-25 \mathrm{MPa}$ & $0.1 \mathrm{MPa}$ \\
\hline Albite & \multicolumn{5}{|c|}{$\mathrm{NaAlSi} \mathrm{O}_{8}+4 \mathrm{H}^{+}=\mathrm{Al}^{3+}+\mathrm{Na}^{+}+2 \mathrm{H}_{2} \mathrm{O}+3 \mathrm{SiO}_{2(\mathrm{aq})}$} \\
\hline Isobar & -0.239 & 0.755 & 1.495 & 1.803 & 2.086 \\
\hline Anisobar & 2.397 & 2.513 & 2.3750 & 2.244 & \\
\hline Anhydrite & \multicolumn{5}{|c|}{$\mathrm{CaSO}_{4}=\mathrm{Ca}^{2+}+\mathrm{SO}_{4}^{2-}$} \\
\hline Isobar & -6.057 & -5.337 & -4.773 & -4.527 & -4.298 \\
\hline Anisobar & -4.849 & -4.531 & -4.370 & -4.325 & \\
\hline Annite & \multicolumn{5}{|c|}{$\mathrm{KFe}_{3} \mathrm{AlSi}_{3} \mathrm{O}_{10}(\mathrm{OH})_{2}+10 \mathrm{H}^{+}=\mathrm{Al}^{3+}+\mathrm{K}^{+}+3 \mathrm{Fe}^{2+}+3 \mathrm{SiO}_{2(\mathrm{aq})}+6 \mathrm{H}_{2} \mathrm{O}$} \\
\hline Isobar & 24.655 & 26.512 & 27.810 & 28.330 & 28.799 \\
\hline Anisobar & 28.713 & 29.218 & 29.165 & 29.009 & \\
\hline Boehmite & \multicolumn{5}{|c|}{$\mathrm{AlO}_{2} \mathrm{H}+3 \mathrm{H}^{+}=\mathrm{Al}^{3+}+2 \mathrm{H}_{2} \mathrm{O}$} \\
\hline Isobar & 7.44 & 7.964 & 8.3300 & 8.475 & 8.606 \\
\hline Anisobar & 7.953 & 8.306 & 8.5010 & 8.561 & \\
\hline Calcite & \multicolumn{5}{|c|}{$\mathrm{CaCO}_{3}+\mathrm{H}^{+}=\mathrm{Ca}^{2+}+\mathrm{HCO}_{3}^{-}$} \\
\hline Isobar & 0.715 & 1.198 & 1.560 & 1.713 & 1.8530 \\
\hline Anisobar & 1.686 & 1.846 & 1.8840 & 1.875 & \\
\hline Chalcedony & \multicolumn{5}{|c|}{$\mathrm{SiO}_{2}=\mathrm{SiO}_{2(\mathrm{aq})}$} \\
\hline Isobar & -3.948 & -3.861 & -3.789 & -3.757 & -3.728 \\
\hline Anisobar & -3.352 & -3.463 & -3.590 & -3.658 & \\
\hline $\mathrm{Fe}(\mathrm{OH})_{3}$ & \multicolumn{5}{|c|}{$\mathrm{Fe}(\mathrm{OH})_{3}+3 \mathrm{H}^{+}=\mathrm{Fe}^{3+}+3 \mathrm{H}_{2} \mathrm{O}$} \\
\hline Isobar & 4.942 & 5.318 & 5.5650 & 5.659 & 5.7410 \\
\hline
\end{tabular}




\begin{tabular}{|c|c|c|c|c|c|}
\hline \multirow[t]{2}{*}{ Minerals } & \multicolumn{5}{|c|}{ Reactions and $\log K\left(25^{\circ} \mathrm{C}, P\right)$ calculated with THERMO-ZNS } \\
\hline & $-150 \mathrm{MPa}$ & $-100 \mathrm{MPa}$ & $-50 \mathrm{MPa}$ & $-25 \mathrm{MPa}$ & $0.1 \mathrm{MPa}$ \\
\hline Anisobar & 5.8460 & 5.9210 & 5.8670 & 5.810 & \\
\hline Gibbsite & \multicolumn{5}{|c|}{$\mathrm{Al}(\mathrm{OH})_{3}+3 \mathrm{H}^{+}=\mathrm{Al}^{3+}+3 \mathrm{H}_{2} \mathrm{O}$} \\
\hline Isobar & 5.9730 & 6.436 & 6.747 & 6.865 & 6.9710 \\
\hline Anisobar & 6.8130 & 6.996 & 7.0270 & 7.006 & \\
\hline Goethite & \multicolumn{5}{|c|}{$\mathrm{FeOOH}+3 \mathrm{H}^{+}=\mathrm{Fe}^{3+}+2 \mathrm{H}_{2} \mathrm{O}$} \\
\hline Isobar & -0.3420 & 0.086 & 0.378 & 0.493 & 0.5960 \\
\hline Anisobar & 0.206 & 0.451 & 0.5610 & 0.585 & \\
\hline Hematite & \multicolumn{5}{|c|}{$\mathrm{Fe}_{2} \mathrm{O}_{3}+6 \mathrm{H}^{+}=2 \mathrm{Fe}^{+3}+3 \mathrm{H}_{2} \mathrm{O}$} \\
\hline Isobar & -1.954 & -1.0290 & -0.380 & -0.118 & 0.1170 \\
\hline Anisobar & -1.1580 & -0.4980 & -0.114 & 0.015 & \\
\hline K-Feldspar & \multicolumn{5}{|c|}{$\mathrm{KAlSi}_{3} \mathrm{O}_{8}+4 \mathrm{H}^{+}=\mathrm{Al}^{3+}+\mathrm{K}^{+}+2 \mathrm{H}_{2} \mathrm{O}+3 \mathrm{SiO}_{2(\mathrm{aq})}$} \\
\hline Isobar & -3.218 & -2.249 & -1.530 & -1.230 & -0.953 \\
\hline Anisobar & -0.355 & -0.340 & -0.574 & -0.751 & \\
\hline Kaolinite & \multicolumn{5}{|c|}{$\mathrm{Al}_{2} \mathrm{Si}_{2} \mathrm{O}(\mathrm{OH})_{4}+6 \mathrm{H}^{+}=2 \mathrm{Al}^{3+}+2 \mathrm{SiO}_{2(\mathrm{aq})}+5 \mathrm{H}_{2} \mathrm{O}$} \\
\hline Isobar & 2.7750 & 3.9610 & 4.804 & 5.1430 & 5.4510 \\
\hline Anisobar & 5.392 & 5.706 & 5.678 & 5.581 & \\
\hline Phlogopite & \multicolumn{5}{|c|}{$\mathrm{KAlMg}_{3} \mathrm{Si}_{3} \mathrm{O}_{10}(\mathrm{OH})_{2}+10 \mathrm{H}^{+}=\mathrm{Al}^{3+}+\mathrm{K}^{+}+3 \mathrm{Mg}^{2+}+3 \mathrm{SiO}_{2(\mathrm{aq})}+6 \mathrm{H}_{2} \mathrm{O}$} \\
\hline Isobar & 35.846 & 35.846 & 35.846 & 36.333 & 36.770 \\
\hline Anisobar & 32.862 & 34.618 & 37.160 & 36.992 & \\
\hline Quartz & \multicolumn{5}{|c|}{$\mathrm{SiO}_{2}=\mathrm{SiO}_{2(\mathrm{aq})}$} \\
\hline
\end{tabular}




\begin{tabular}{|l|l|l|l|l|l|}
\hline Minerals & \multicolumn{5}{|c|}{ Reactions and $\log K\left(\mathbf{2 5}{ }^{\circ} \mathbf{C}, \boldsymbol{P}\right)$ calculated with THERMO-ZNS } \\
\hline & $-\mathbf{1 5 0} \mathbf{~ M P a}$ & $-\mathbf{1 0 0} \mathbf{~ M P a}$ & $\mathbf{- 5 0} \mathbf{~ M P a}$ & $\mathbf{- 2 5} \mathbf{~ M P a}$ & $\mathbf{0 . 1} \mathbf{~ M P a}$ \\
\hline Isobar & -4.221 & -4.132 & -4.060 & -4.029 & -3.9993 \\
\hline Anisobar & -3.623 & -3.734 & -3.861 & -3.929 & \\
\hline \multicolumn{5}{|l}{} \\
\hline $\mathrm{SiO}_{2(\mathrm{am})}$ & $\mathrm{SiO}_{2}=\mathrm{SiO}_{2(\mathrm{aq})}$ & -2.957 & -2.830 & -2.771 & -2.7136 \\
\hline Isobar & -3.1 & -2.448 & -2.575 & -2.643 & \\
\hline Anisobar & -2.337 & &
\end{tabular}

